Prepared in cooperation with the Bureau of Reclamation

\title{
Demographics and Run Timing of Adult Lost River (Deltistes luxatus) and Shortnose (Chasmistes brevirostris) Suckers in Upper Klamath Lake, Oregon, 2011
}

Open-File Report 2012-1193 



\section{Demographics and Run Timing of Adult Lost River (Deltistes luxatus) and Shortnose (Chasmistes brevirostris) Suckers in Upper Klamath Lake, Oregon, 2011}

By David A. Hewitt, Eric C. Janney, Brian S. Hayes, and Alta C. Harris

Prepared in cooperation with the Bureau of Reclamation

Open-File Report 2012-1193 


\section{U.S. Department of the Interior \\ KEN SALAZAR, Secretary}

\section{U.S. Geological Survey \\ Marcia K. McNutt, Director}

U.S. Geological Survey, Reston, Virginia: 2012

For more information on the USGS-the Federal source for science about the Earth, its natural and living resources, natural hazards, and the environment, visit http://www.usgs.gov or call 1-888-ASK-USGS.

For an overview of USGS information products, including maps, imagery, and publications, visit http://www.usgs.gov/pubprod

To order this and other USGS information products, visit $h$ ttp://store.usgs.gov

Suggested citation:

Hewitt, D.A., Janney, E.C., Hayes, B.S., and Harris, A.C., 2012, Demographics and run timing of adult Lost River (Deltistes luxatus) and shortnose (Chasmistes brevirostris) suckers in Upper Klamath Lake, Oregon, 2011: U.S. Geological Survey Open-File Report 2012-1193, 42 p.

Any use of trade, product, or firm names is for descriptive purposes only and does not imply endorsement by the U.S. Government.

Although this report is in the public domain, permission must be secured from the individual copyright owners to reproduce any copyrighted material contained within this report. 


\section{Contents}

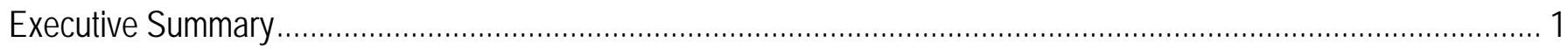

Introduction

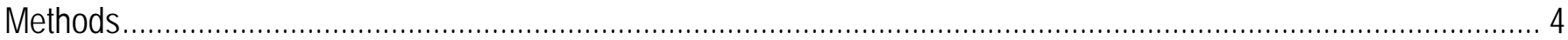

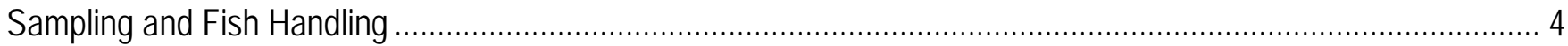

Remote Passive Integrated Transponder Tag Detection Systems .............................................................. 5

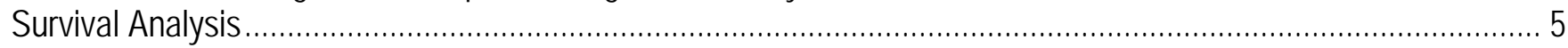

Recruitment and Population Rate of Change

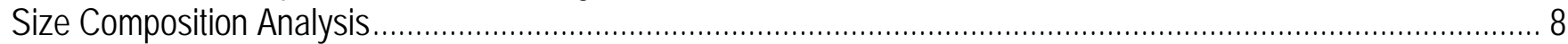

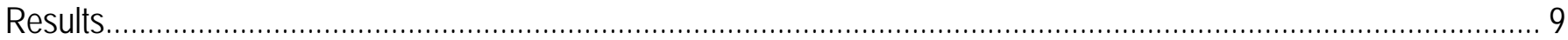

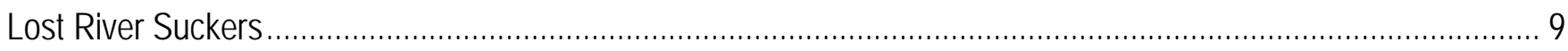

Catch Summary and Run Timing for 2011 ...................................................................................... 9

Survival, Recruitment, and Size Composition.....................................................................................

Upper Klamath Lake Lakeshore Spawning Subpopulation ..................................................................10

Williamson and Sprague River Spawning Subpopulation .......................................................................11

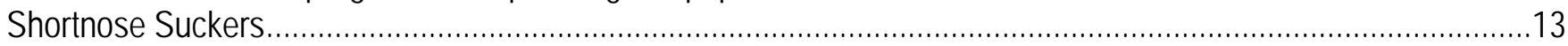

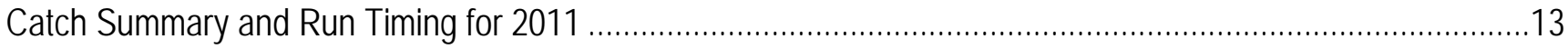

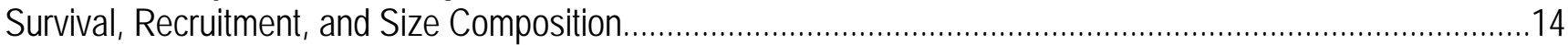

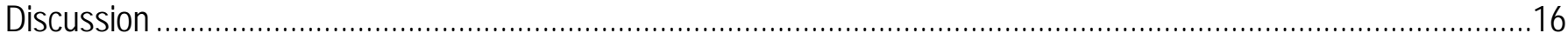

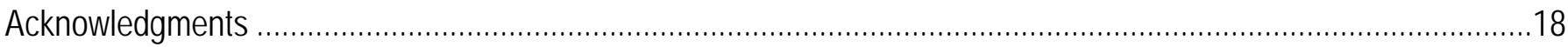

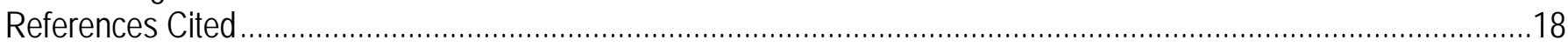

\section{Figures}

Figure 1. Map showing sampling locations for Lost River suckers and shortnose suckers in

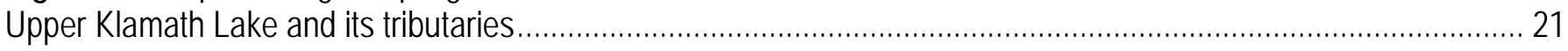

Figure 2. Seasonality of trammel net captures of Lost River suckers at lakeshore springs, 2011 .......................... 22

Figure 3. Seasonality of detections of Lost River suckers on remote passive integrated transponder

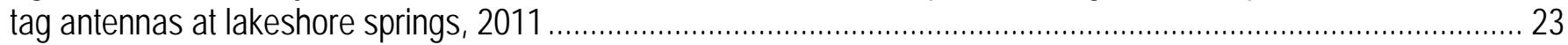

Figure 4. Seasonality of captures of Lost River suckers in the upstream trap of the Williamson River weir, 2011 ... 24

Figure 5. Seasonality of detections of Lost River suckers on the remote passive integrated transponder tag antenna at the upstream trap of the Williamson River weir, 2011 ................................................................. 25

Figure 6. Seasonality of detections of Lost River suckers on the remote passive integrated transponder tag antenna array across the Sprague River just downstream of the Chiloquin Dam site, 2011.............................. 26

Figure 7. Model-averaged estimates of apparent annual survival probability and derived population rate of change for Lost River suckers from the lakeshore spawning subpopulation, 1999-2009........................................ 27

Figure 8. Realized proportional change in the size of the lakeshore spawning subpopulation of Lost River

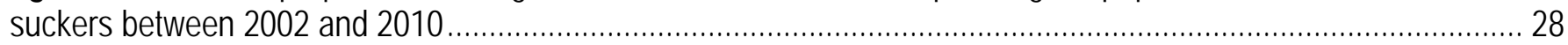

Figure 9. Boxplots of fork lengths of Lost River suckers captured in trammel nets at lakeshore springs,

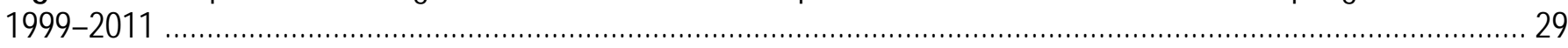

Figure 10. Model-averaged estimates of apparent annual survival probability and derived population rate of change for Lost River suckers from the river spawning subpopulation, 2000-2009 ....................................... 30

Figure 11. Boxplots of fork lengths of Lost River suckers captured at pre-spawn staging areas in Upper Klamath Lake and in the Williamson and Sprague Rivers, 2000-2011...................................................... 31

Figure 12. Realized proportional change in the size of the river spawning subpopulation of Lost River suckers between 2002 and 2010. 
Figure 13. Seasonality of detections of shortnose suckers on the remote passive integrated transponder tag antenna at the upstream trap of the Williamson River weir, 2011.

Figure 14. Seasonality of detections of shortnose suckers on the remote passive integrated transponder tag antenna array across the Sprague River just downstream of the Chiloquin Dam site, 2011..................................... 34

Figure 15. Model-averaged estimates of apparent annual survival probability and derived population rate of change for shortnose suckers, 2001-2009

Figure 16. Realized proportional change in the size of the spawning population of shortnose suckers between 2001 and 2010 36

Figure 17. Boxplots of fork lengths of shortnose suckers captured in Upper Klamath Lake and the Williamson and Sprague Rivers, 2000-2011

\section{Tables}

Table 1. Numbers of Lost River and shortnose suckers captured in Upper Klamath Lake and the Williamson River between 2003 and 2011

Table 2. Numbers of Lost River and shortnose suckers detected by remote antennas in Upper Klamath Lake and its tributaries in 2011 39

Table 3. Model selection results for the top eight capture-recapture models fitted to the data for the lakeshore spawning subpopulation of Lost River suckers, 1999-2011

Table 4. Model selection results for the top five capture-recapture models fitted to the data for the river spawning subpopulation of Lost River suckers, 2000-2011

Table 5. Model selection results for the top nine capture-recapture models fitted to the data for the shortnose sucker population, 1999-2011. 


\section{Conversion Factors and Acronyms}

\section{Conversion Factors}

SI to Inch/Pound

\begin{tabular}{lcc}
\hline \multicolumn{1}{c}{ Multiply } & By & To obtain \\
\hline centimeter $(\mathrm{cm})$ & Length & \\
millimeter $(\mathrm{mm})$ & 0.3937 & inch (in.) \\
meter $(\mathrm{m})$ & 0.03937 & inch (in.) \\
kilometer $(\mathrm{km})$ & 3.281 & foot (ft) \\
\hline & 0.6214 & mile $(\mathrm{mi})$ \\
\hline cubic meter per second $\left(\mathrm{m}^{3} / \mathrm{s}\right)$ & Flow rate & \\
\hline
\end{tabular}

Temperature in degrees Celsius $\left({ }^{\circ} \mathrm{C}\right)$ may be converted to degrees Fahrenheit $\left({ }^{\circ} \mathrm{F}\right)$ as follows:

${ }^{\circ} \mathrm{F}=\left(1.8 \mathrm{x}^{\circ} \mathrm{C}\right)+32$

\section{Acronyms}

CJS

FL

LRS

PIT

SNS

UKL

USGS

\author{
Cormack-Jolly-Seber \\ fork length \\ Lost River sucker \\ passive integrated transponder \\ shortnose sucker \\ Upper Klamath Lake \\ U.S. Geological Survey
}


This page left intentionally blank 


\section{Demographics and Run Timing of Adult Lost River (Deltistes luxatus) and Shortnose (Chasmistes brevirostris) Suckers in Upper Klamath Lake, Oregon, 2011}

By David A. Hewitt, Eric C. Janney, Brian S. Hayes, and Alta C. Harris

\section{Executive Summary}

Data from a long-term capture-recapture program were used to assess the status and dynamics of populations of two long-lived, federally endangered catostomids in Upper Klamath Lake, Oregon. Lost River suckers (Deltistes luxatus) and shortnose suckers (Chasmistes brevirostris) have been captured and tagged with passive integrated transponder (PIT) tags during their spawning migrations in each year since 1995. In addition, beginning in 2005, individuals that had been previously PIT-tagged were reencountered on remote underwater antennas deployed throughout sucker spawning areas. Captures and remote encounters during spring 2011 were used to describe the spawning migrations in that year and also were incorporated into capture-recapture analyses of population dynamics.

Cormack-Jolly-Seber (CJS) open population capture-recapture models were used to estimate annual survival probabilities, and a reverse-time analog of the CJS model was used to estimate recruitment of new individuals into the spawning populations. In addition, data on the size composition of captured fish was examined to provide corroborating evidence of recruitment. Survival and recruitment estimates were used to derive estimates of changes in population size over time and to determine the status of the populations in 2010. Separate analyses were conducted for each species and also for each subpopulation of Lost River suckers (LRS). One subpopulation of LRS migrates into tributaries to spawn, similar to shortnose suckers (SNS), whereas the other subpopulation spawns at upwelling areas along the eastern shoreline of the lake.

In 2011, we captured, tagged, and released 806 LRS at four lakeshore spawning areas and recaptured an additional 1,006 individuals that had been tagged in previous years. Across all four areas, the remote antennas detected 6,547 individual LRS during the spawning season. Spawning activity peaked in April and most individuals were encountered at Sucker Springs and Cinder Flats. In the Williamson River, we captured, tagged, and released 2,742 LRS and 123 SNS, and recaptured 376 LRS and 58 SNS that had been tagged in previous years. Remote PIT tag antennas in the traps at the weir on the Williamson River and remote antenna systems that spanned the river at four different locations on the Williamson and Sprague Rivers detected a total of 16,494 LRS and 5,450 SNS. Most LRS passed upstream between mid-April and mid-May when water temperatures were rising and near or greater than $10^{\circ} \mathrm{C}$. In contrast, the largest peaks in upstream passage of SNS occurred in early and mid-May when water temperatures were rising and near or greater than $12{ }^{\circ} \mathrm{C}$. Finally, an additional $875 \mathrm{LRS}$ and 1,600 SNS were captured in trammel net sampling at pre-spawn staging areas in the northeastern portion of the lake. Of these, 191of the LRS and 571 of the SNS had been PIT-tagged in previous years. For 
LRS, encounter histories showed that more than 90 percent of the fish captured at the staging areas were members of the subpopulation that spawns in the tributaries.

Capture-recapture analyses for the LRS subpopulation that spawns at the shoreline areas included encounter histories for more than 10,500 individuals, and analyses for the subpopulation that spawns in the tributaries included more than 22,000 encounter histories. With a few exceptions, the survival of males and females in both subpopulations was high (greater than 0.9) between 1999 and 2009. Notably lower survival occurred for both sexes from the tributaries in 2000, for both sexes from the shoreline areas in 2002, and for males from the tributaries in 2006. Between 2001 and 2010, the abundance of males in the lakeshore spawning subpopulation decreased by 50-60 percent and the abundance of females decreased by 29-44 percent. Capture-recapture models suggested that the abundance of the river spawning subpopulation of LRS has increased substantially since 2006. The increase over this period was largely due to large estimated recruitment events in 2003, 2006, and 2008. We know that the estimate in 2006 is substantially biased in favor of recruitment due to a sampling issue. We are skeptical of the magnitude of recruitment indicated by the 2003 and 2008 estimates as well because very few small individuals that would indicate the presence of new recruits were captured in those years. If we assume that little or no recruitment has occurred, the abundance of both sexes in the river spawning subpopulation decreased by more than 40 percent between 2002 and 2010 .

Capture-recapture analyses for SNS included encounter histories for more than 15,500 individuals. The majority of annual survival estimates between 2001 and 2009 were high (greater than 0.8), but SNS did experience more years of low survival than either LRS subpopulation. The survival of both sexes was particularly low in both 2001 and 2004, and male survival also was somewhat low in 2002 and 2006. Capture-recapture models and size composition data indicated that recruitment of new individuals into the SNS spawning population was trivial in nearly all years between 2001 and 2009. As a result, the abundance of males decreased by 64-82 percent and the abundance of females decreased by 62-76 percent between 2001 and 2010.

Despite relatively high survival in most years, both species have experienced substantial declines in the abundance of spawning fish because losses from mortality have not been balanced by recruitment of new individuals. Although capture-recapture data indicate substantial recruitment of new individuals into the adult spawning populations for SNS and river spawning LRS in some years, size data do not corroborate these estimates. In fact, fork length data indicate that all populations are largely comprised of fish that were present in the late 1990s and early 2000s. As a result, the status of the endangered sucker populations in Upper Klamath Lake remains worrisome, and the situation is most dire for shortnose suckers. Future investigations should explore the connections between sucker recruitment and survival and various environmental factors, such as water quality and disease. Our monitoring program provides a robust platform for estimating vital population parameters, evaluating the status of the populations, and assessing the effectiveness of conservation and recovery efforts. 


\section{Introduction}

Lost River suckers (Deltistes luxatus) and shortnose suckers (Chasmistes brevirostris) are longlived catostomids that are endemic to the Upper Klamath River basin in southern Oregon and northern California (Scoppettone and Vinyard, 1991). Historical accounts indicate that both species once were extremely abundant throughout the upper basin and were used in a subsistence fishery by Native Americans and later in a popular recreational snag fishery that was closed in 1987 (Markle and Cooperman, 2002). Declining population abundance trends and range reductions were noted for both species as early as the mid-1960s. The extent of these declines was not evident, however, until the mid1980s, when recreational catch rates exhibited dramatic decreases that were attributed in part to overfishing (Markle and Cooperman, 2002; National Research Council, 2004). Estimated annual fishery harvest of spawning suckers in the Williamson and Sprague Rivers, tributaries to Upper Klamath Lake in Oregon, decreased from more than 10,000 fish in 1968 to 687 fish in 1985 (Markle and Cooperman, 2002). In addition to decreasing catches, age data from suckers collected during a 1986 fish die-off indicated that the Lost River sucker (LRS) population was composed of old individuals and that no substantial recruitment had occurred during the previous 15 years (Scoppettone and Vinyard, 1991; U.S. Fish and Wildlife Service, 1993). These findings led to the federal listing of both species under the Endangered Species Act in 1988. Upper Klamath Lake contains the largest remaining population of Lost River suckers (National Research Council, 2004) and one of the largest remaining populations of shortnose suckers.

Life history and spawning characteristics of suckers in Upper Klamath Lake are reasonably well documented (Scoppettone and Vinyard, 1991; Moyle, 2002; Cooperman and Markle, 2003). Age estimates for Lost River suckers have exceeded 50 years and age estimates for shortnose suckers (SNS) have exceeded 30 years (National Research Council, 2004; Terwilliger and others, 2010). Both species are obligate lake dwellers that make spawning migrations between March and May of each year. Shortnose suckers spawn primarily in the Williamson and Sprague Rivers, but two distinct subpopulations of Lost River suckers have been identified in Upper Klamath Lake (National Research Council, 2004). One subpopulation spawns in the Williamson and Sprague Rivers, and the other subpopulation spawns at several spring upwelling areas along the eastern shoreline of the lake below Modoc Rim (fig. 1). Capture-recapture data show an extremely high degree of spawning site fidelity and little reproductive mixing between the two subpopulations (Janney and others, 2008).

Although fishing mortality was eliminated with the closure of the recreational fishery in 1987, poor survival of adult suckers is still considered a factor that can potentially limit recovery of Upper Klamath Lake populations (Janney and others, 2008). Upper Klamath Lake has progressed to a hypereutrophic state due to increased nutrient loading from wetland drainage, grazing, and timber harvest (Bradbury and others, 2004; Eilers and others, 2004). These conditions lead to massive blooms of the cyanobacterium Aphanizomenon flos-aquae between June and October of each year (Kann and Smith, 1999; Wood and others, 2006; Lindenberg and others, 2009). The algal blooms and their subsequent die-offs produce water quality conditions that are deleterious to fish health-low concentrations of dissolved oxygen, elevated concentrations of ammonia, and high $\mathrm{pH}$. Poor water quality conditions are thought to have contributed to a number of substantial fish die-offs in the lake, most recently during the summers of 1986, 1995, 1996, 1997 (Perkins and others, 2000; National Research Council, 2004), and, to a much lesser extent, in the summer of 2003 (U.S. Geological Survey, unpub. data, 2003). 
In this report, we summarize data collected in 2011 on the timing and magnitude of adult sucker spawning migrations and analyze capture-recapture data from 1999 to 2011 to evaluate demographic trends in LRS and SNS populations. Annual adult survival and recruitment were modeled and compared to assess differences attributable to species, LRS subpopulation, sex, and year. We used model-averaged estimates of these probabilities to calculate estimates of population rate of change and determine status as of spring 2010. In addition to estimating recruitment from capture-recapture data, we assessed relative changes in size composition to provide additional insight into the relative frequency and magnitude of recruitment into the adult spawning populations.

\section{Methods}

\section{Sampling and Fish Handling}

The Lost River sucker subpopulation that spawns at spring upwelling areas along the eastern shoreline of Upper Klamath Lake was sampled at four locations (fig. 1) using $30 \mathrm{~m}$ trammel nets (1.8 m high; two $30 \mathrm{~cm}$ mesh outer panels; one $3.8 \mathrm{~cm}$ mesh inner panel; foam-core float line; lead-core bottom line). Nets generally were set twice per week at each spawning area (hereafter, spring) between February and May from 1999 to 2011. The only exception to this sampling schedule occurred in 2006, when each spring was sampled only once per week. Nets were set starting at the shoreline and extending out in a semicircular fashion, encompassing the area where spawning activity was concentrated.

Lost River and shortnose suckers also were sampled at two locations within tributary rivers. Between 2000 and 2008, fish were sampled three times per week at the Chiloquin Dam fish ladder on the Sprague River (fig. 1). Before sampling, a screen was placed over the bottom entrance (outflow) to prevent fish from exiting, and the upstream end (inflow) was blocked by a board to lower the water level in the cells of the fish ladder. A combination of dip nets and short trammel nets were then used to collect fish trapped in the ladder. Chiloquin Dam and the associated fish ladder were removed from the river in fall 2008. Beginning in 2005 and continuing through 2011, a resistance board weir [described in detail by Tobin (1994)] was deployed on the Williamson River at river kilometer 10 to improve capture rates of suckers during the spawning migrations (fig. 1). The weir restricted the passage of suckers to two short sections, each fitted with a live trap. An upstream trap was used to capture fish as they migrated upriver, and a downstream trap was used to allow downriver migrating suckers to pass the weir. High flows in the Williamson River during most of the 2006 spawning season inundated the weir and allowed fish to pass over and around the weir without swimming through the trap.

Additional trammel net sampling for pre-spawn adult suckers of both species was conducted from 1995 to 2011 at various pre-spawning staging areas in Upper Klamath Lake. The overwhelming majority of this type of sampling in recent years has taken place near Modoc Point and Goose Bay (fig. 1). In addition, between 1995 and 2006, pre-spawn suckers were sampled with trammel nets in the lowest couple kilometers of the Williamson River (Janney and others, 2006).

Suckers captured at all sample locations were identified to species and sex, measured for fork length (FL), and scanned for the presence of a passive integrated transponder (PIT) tag. If a PIT tag was not detected, one was inserted into the ventral abdominal musculature anterior to the pelvic girdle. From 1995 to 2004, suckers were tagged with $125 \mathrm{kHz}$ full-duplex PIT tags. All tagging since the 2005 sampling season has used $134.2 \mathrm{kHz}$ full-duplex tags. All fish were released soon after being tagged. 


\section{Remote Passive Integrated Transponder Tag Detection Systems}

In addition to capture sampling, detections of PIT-tagged fish on remote antennas were incorporated into the capture-recapture study design beginning in 2005. Remote antennas were incorporated to improve the probability of re-encountering previously tagged suckers (Hewitt and others, 2010). Suckers detected by these systems were not physically handled, but were confirmed to be alive and thus were considered live recaptures in survival analyses. Locations of remote PIT tag detection systems are shown in figure 1, and are listed here with the range of years during which they were operational:

- $\quad$ antennas on the substrate at lakeshore springs in Upper Klamath Lake (limited in 2005, full implementation in 2006-2011);

- $\quad$ one antenna in each of the upstream and downstream traps of the Williamson River weir (20052011);

- a river-wide antenna array on the substrate immediately upstream of the weir (2007-2011);

- a river-wide antenna array on the substrate immediately downstream of the Chiloquin Dam site (2008-2011);

- $\quad$ antennas in the entrance, middle, and exit of the Chiloquin Dam fish ladder (2006-2008);

- a river-wide antenna array on the substrate about 2.5 river kilometers upstream of the Chiloquin Dam site (2007-2011); and

- a river-wide antenna array on the substrate about 12 river kilometers upstream of the Chiloquin Dam site at Braymill (2008-2011).

\section{Survival Analysis}

We used Cormack-Jolly-Seber (CJS) live-recapture models (Williams and others, 2002; Nichols, $2005)$ to obtain maximum likelihood estimates of apparent survival $(\Phi)$ and re-encounter $(p)$ probabilities. Apparent survival is the complement of the sum of mortality and permanent emigration from the study area (Pollock and others, 2007). Radio telemetry data indicate that emigration from Upper Klamath Lake and its tributaries by either sucker species is rare (Reiser and others, 2001; Banish and others, 2009). Similarly, detections of PIT-tagged suckers on remote antennas within the fish ladder at Link River Dam (the southern outlet of the lake), as well as captures of PIT-tagged suckers in Bureau of Reclamation trammel net sampling in Lake Ewauna (downstream of the Link River), have recorded fewer than 10 suckers emigrating from Upper Klamath Lake via the Link River. Therefore, we expect that our estimates of apparent survival are nearly equivalent to true survival. Lost River sucker data were analyzed separately for the two spawning subpopulations-lakeshore spawners and river spawners.

The CJS model makes the following assumptions: (1) tags are not lost, or missed when individuals are re-encountered; (2) sampling periods are "instantaneous" relative to the interval between samples; and (3) there is no unmodeled individual variability (heterogeneity) in survival or re-encounter probabilities among the tagged individuals. Although double-tagging experiments with Floy and PIT tags showed that PIT tag loss rates were less than 1 percent over 3 or more years (U.S. Geological Survey, unpub. data, 2010), an unknown proportion of the $125 \mathrm{kHz}$ PIT tags released in 2001-2003 are not detectable on the remote antennas. For physical recaptures, we ensured that tags were not missed when present by scanning a test tag prior to scanning each fish, and also scanning a test tag after each fish that was found to be untagged. Regarding Assumption 2, sampling in our study occurs over a 3-3.5 month spawning period and is not instantaneous. However, the vast majority of captures and encounters occur over a much shorter time period, and individuals are fairly consistent from year to year in the 
relative times at which they join the spawning aggregations. Thus, on an individual basis, sampling can be considered nearly instantaneous relative to an annual interval used for parameter estimation. In addition, spawning fish almost always appear to be in excellent condition and water quality is good during the spring. Thus, we expect that little mortality occurs during the sampling period and does not bias survival estimates.

We assessed whether our data conformed to the assumptions of the CJS model using goodnessof-fit testing in the program U-CARE (Choquet and others, 2009). Goodness-of-fit tests pooled over time indicated significant departures from frequencies expected under the CJS model for Lost River sucker subpopulations and for shortnose suckers. Lack of fit can be an indication of model assumption violations, sparse data, or lack of independence. Closer examination of our goodness-of-fit tests for individual time periods revealed no consistent or systematic bias that would suggest tagging effects. Lack of fit in our data probably was due to a combination of sparse recaptures at the beginning of the study and lack of independence. The lack of independence, or overdispersion, probably results from schooling behavior and is relatively common in capture-recapture studies of schooling fish (Pollock and others, 2007). An overdispersion correction factor (ĉ) was determined from the most general model for each species or subpopulation by use of the median c estimation method in program MARK (Cooch and White, 2010). These $\hat{c}$ values were applied to the respective set of candidate models to compensate for overdispersion in model selection statistics and to inflate variances associated with parameter estimates. Applying a variance inflation factor is recommended when heterogeneity is detected in the data, and supports a conservative approach to inference based on model selection (Anderson and others, 1994).

Model sets were developed by considering the effects of sex and time (year) on $\Phi$ and $p$, and then including models with and without those factors. We modeled $\Phi$ as a function of sex because past analyses have shown that female suckers often have higher survival than males (Janney and others, 2008; Hewitt and others, 2011). Most importantly, we modeled $\Phi$ as a function of time to detect changes in annual survival. For $p$, we expected sex to be important because of differences in reproductive behavior (for example, males stay at spawning areas longer than females, potentially increasing their probability of being encountered), and we expected time to be important because of annual differences in sampling intensity and environmental effects on the condition of the spawning habitat. Past analyses showed that models with some combination of both sex and time effects on $p$ were overwhelmingly supported in model selection, so we only considered models with some combination of both effects (Janney and others, 2009). We included models with both additive and interactive effects for $\Phi$ and $p$. Additive models constrained effects to be the same between groups across time (for example, the difference between male and female survival is the same in each year), whereas interactive models included more parameters and allowed effects to vary through time (for example, separate estimates of survival for each sex in each year). Note that, as in many CJS designs, the last estimates of $\Phi$ and $p$ are confounded in the likelihood and cannot be separately estimated. As such, we do not report or discuss estimates of $\Phi$ for 2010 or $p$ for 2011.

The models used in the analysis were specified and passed to program MARK (White and Burnham, 1999) using the RMark package (Laake, 2010; Laake and Rexstad, 2010) within the R software environment (R Development Core Team, 2010). All model likelihoods were constructed using a logit link function and optimized using the default Newton-Raphson algorithm. We used Akaike's information criterion corrected for small sample bias and adjusted for overdispersion (quasilikelihood AICc, or QAICc) as a statistical criterion to evaluate the competing models (Burnham and Anderson, 2002). Akaike weights $\left(w_{i}\right)$ are reported as a measure of the relative weight among the models, or the likelihood of each model being the best model in the set given the data. Rather than making inferences from only the best model in the set, the one with the smallest QAICc value, parameter estimates were 
model-averaged using the $w_{i}$ as weights. Model-averaged parameter estimates account for model selection uncertainty in the estimated precision of the parameters and thus produce unconditional estimates of variances and standard errors (Buckland and others, 1997).

\section{Recruitment and Population Rate of Change}

A primary requirement for recovering the endangered sucker populations is knowledge of changes in population size over time. In addition to survival, recruitment can be estimated from open population capture-recapture data (Pradel, 1996; Franklin, 2001; Nichols, 2005). Specifically, the reverse-time analog of survival can be estimated; this parameter is termed seniority and denoted $\gamma$. Seniority is defined as the probability that an animal present in the sampled population at period $i$ was also present in period $i-1$. Given estimates of $\Phi$ and $\gamma$, population rate of change $\left(\lambda_{i}=N_{i+1} / N_{i}\right)$, can be estimated without estimating $N$ using the equation:

$$
\lambda_{i}=\frac{\phi_{i}}{\gamma_{i+1}}
$$

Pradel (1996) introduced a likelihood that models the entire encounter history and is based on the temporal symmetry of capture-recapture data (Nichols and Hines, 2002). This approach combines probabilities describing forward time (survival) and reverse-time (seniority) processes, allowing the direct estimation and modeling of $\lambda$. The assumptions of the temporal symmetry model are similar to those in the Cormack-Jolly-Seber model, but temporal symmetry further assumes that the study area is well defined and does not expand over time and that there is no permanent trap response in encounter probability. The incorporation of remote PIT tag detection systems into our study design in 2005 created a situation in which previously tagged fish have a much greater probability of being re-encountered than untagged fish have of being captured in trammel nets. In essence, the remote antenna systems create a dramatic "trap-happy" response in encounter probability (Otis and others, 1978). This difference in encounter probabilities does not cause bias in survival estimates from CJS models, but it does cause substantial bias in estimates of seniority and population rate of change from temporal symmetry models (Hines and Nichols, 2002).

To avoid such bias, we obtained estimates of survival and seniority from separate model sets and then used the estimates to calculate $\lambda$ with the equation given above. Encounter histories used to model survival included physical captures and remote detections, but seniority models included only physical captures. Early estimates of $\gamma$ are not reported because of poor precision due to sparse data and because simulations have shown that the initial two $\gamma$ estimates are likely to be substantially more biased than subsequent estimates (Hines and Nichols, 2002). Model sets for the seniority analyses were developed and evaluated in a way similar to the survival analyses; however, effects of tag type on $p$ were not included in models for seniority because remote detections were not included. Past seniority analyses for SNS and both subpopulations of LRS have yielded a large portion of seniority parameter estimates from time-dependent models on a boundary of 1.0 (Hewitt and others, 2011). In an attempt to obtain seniority estimates and standard errors that could be used to derive an estimate of $\lambda$ in those years, and to help determine whether estimability issues were the result of sparse recapture data or simply the lack of any measurable recruitment, we developed models that constrained to be the same all years in which $\gamma$ was estimated on a boundary in time-dependent models. These models were considered in model selection along with all other models.

Standard errors for the derived estimates of $\lambda$ were calculated using the Delta method. Ideally, estimates of survival and seniority would be generated from a single likelihood using a temporal symmetry model (Pradel, 1996), and the standard error for $\lambda$ estimates would be corrected for the 
covariance between these two parameters. Our calculation of the standard error of $\lambda$ by the Delta method ignores any covariance between survival and seniority. The effect of this approach on the estimated standard errors is expected to be small, but the presented standard errors for $\lambda$ may be too precise. Derived estimates of $\lambda$ are not reported for years in which survival was estimated on a boundary or both survival and seniority were estimated on a boundary. For years in which seniority was estimated on a boundary but survival was not, $\lambda$ and its standard error were assumed to be equivalent to estimates for survival.

Annual estimates of $\lambda$ provide insight into the variability in abundance of adult spawning populations by showing whether the population decreased $(\lambda<1)$, remained stable $(\lambda=1)$, or increased $(\lambda>1)$. We summarize the long-term dynamics of the populations using a quantity known as $\Delta_{t}$, which is simply the cumulative product of the $\lambda$ estimates over a time period of interest (Anthony and others, 2006). This quantity describes the percentage change in population size from the beginning of the period to the end. Values of $\Delta_{t}$ greater than 1.0 (100 percent) indicate increases in population size and values less than 1.0 indicate decreases in population size. For purposes of calculating $\Delta_{t}, \lambda$ was assumed to be 1.0 in years when both survival and seniority were estimated on a boundary. We emphasize that estimates of $\lambda$ and $\Delta_{t}$ values apply only to the adult spawning populations and are not necessarily representative of changes in the whole populations. Increases in juvenile abundance are not incorporated until those individuals join the spawning aggregations and are fully vulnerable to our sampling. Size composition of the catches in the most recent year, described next, may provide an earlier indication of potential recruitment.

\section{Size Composition Analysis}

Fork lengths of captured suckers were used to assess changes in the size structure of the LRS subpopulations and the SNS population over time. This assessment provides additional evidence about recruitment, or the lack thereof, that can be compared with capture-recapture seniority estimates, and also illustrates trends in growth. Length data were grouped separately for each sex within each population or subpopulation, and we calculated an average annual growth rate for each group by fitting a simple linear regression to the successive medians of the annual length distributions. Data from 1999 to 2011 were included for the lakeshore spawning LRS, and data from 2000 to 2011 were included for river spawning LRS and for SNS.

For the lakeshore spawning LRS and for SNS, length analyses and capture-recapture analyses are focused on the same statistical populations. In contrast, for the river spawning LRS, the two analyses are focused on different statistical populations. In order to focus only on spawning adults, the capturerecapture analysis is restricted to fish that were encountered in either the Williamson River or Sprague River during at least one spawning season and that were never encountered at the lakeshore springs. Many LRS are captured during sampling in Upper Klamath Lake outside of the spawning areas, and these individuals do not enter our capture-recapture analyses until they are encountered at a spawning area (lakeshore springs or one of the rivers). In contrast, the length analysis for the river spawning subpopulation includes all LRS that were never encountered at the lakeshore springs, including fish captured in Upper Klamath Lake that were never encountered at a spawning area. As a result, the length analysis may include data for small LRS that are not yet mature but are staging with the spawners in the lake prior to the spawning migration. This is done intentionally to provide an early indication of recruitment to the spawning subpopulation, if and when recruitment occurs. 


\section{Results}

\section{Lost River Suckers}

\section{Catch Summary and Run Timing for 2011}

We captured 1,812 LRS in trammel nets at the lakeshore springs, 1,006 (56 percent) of which had been tagged prior to the 2011 sampling season (table 1). The percentage of LRS captured at the springs that were previously tagged has increased steadily over the last 9 years, and has been greater than 50 percent for the last 2 years. Trammel net catches at the springs in 2011 began in mid-March and continued through mid-May (fig. 2). Most individuals were first captured at Cinder Flats or Sucker Springs (33 percent each), followed by Silver Building Springs (24 percent) and Ouxy Springs (11 percent). In addition to the fish physically captured in trammel nets, 6,547 PIT-tagged LRS were detected swimming over remote antennas at the lakeshore springs. Antennas at Cinder Flats detected more individuals than antennas at any other spring, but antennas at Sucker Springs detected nearly as many (table 2). Lost River suckers were detected beginning the first week of March and continued to be detected through the end of May (fig. 3). Most individuals joined the spawning aggregations in April. At the lakeshore springs, only 26 percent of the LRS detected on the remote antennas also were physically captured in trammel nets, whereas 92 percent of the PIT-tagged LRS that were physically captured also were detected on the remote antennas.

Trammel net sampling at pre-spawn staging areas captured 875 individual LRS (table 1). Of these, 191 (22 percent) had been tagged prior to the 2011 sampling season. The percentage of LRS captured at the staging areas that were previously tagged has increased slowly but steadily over the last 9 years, although the rate of increase appears to have accelerated somewhat in the most recent years. Of the PIT-tagged LRS captured at the staging areas, 79 percent were subsequently captured or detected somewhere in the Williamson or Sprague Rivers, whereas only 6 percent were later captured or detected at the lakeshore springs. One individual was subsequently captured or detected at both spawning areas.

A total of 3,118 LRS were captured in the upstream trap of the Williamson River weir (table 1). Only 376 (12 percent) had been tagged prior to 2011, continuing the long-term trend of a smaller recapture percentage for LRS in the weir compared to the trammel net sampling at the staging areas. Most individuals were captured in the weir between mid-April and early May (fig. 4). The combination of remote PIT tag antennas at the weir (upstream and downstream traps and the river-wide array) detected a total of 16,213 individuals (table 2). The antenna on the upstream trap showed that the vast majority of detections occurred mid-April to mid-May when water temperatures were $10-13^{\circ} \mathrm{C}$ (fig. 5).

Moving upstream from the Williamson River weir, the river-wide antenna array in the Sprague River just downstream of the Chiloquin Dam site detected 5,094 individual LRS between mid-March and early June (table 2). Most individuals were detected between mid-April and early May when water temperatures were equal to or greater than $10^{\circ} \mathrm{C}$ (fig. 6). The next upstream antenna array, located upstream of the Chiloquin Dam site, detected 974 LRS between March 24 and June 12. The farthest upstream array on the Sprague River, located at Braymill, detected 70 individual LRS between March 25 and June 14. 


\section{Survival, Recruitment, and Size Composition}

\section{Upper Klamath Lake Lakeshore Spawning Subpopulation}

From 1999 to 2010, we captured, tagged, and released 4,115 female and 5,985 male Lost River suckers at the lakeshore springs. Excluding re-encounters in the year of tagging, we subsequently recaptured or remotely detected 3,478 (85 percent) of the females and 4,465 (75 percent) of the males on at least one occasion through 2011. An additional 236 females and 283 males from this subpopulation that were captured and tagged previously or elsewhere and then re-encountered at the springs between 1999 and 2010 also were included in the survival analysis.

Thirty-five CJS models were fitted to the encounter histories of fish in this subpopulation to estimate apparent annual survival and re-encounter probabilities. The top model in the set accounted for the vast majority of the weight in the model set $\left(w_{i}=0.90\right.$; table 3$)$. This model included an additive effect of sex and year for $\Phi$, and sex, year, and tag type effects for $p$. The second best model $\left(w_{i}=0.08\right)$ included separate $\Phi$ parameters for each sex in each year (a fully interactive model) and the same structure for $p$ as in the best model. Model-averaged estimates of $\Phi$ varied across years and female survival was consistently, albeit only slightly, higher than male survival (fig. 7). With the exception of 2002, survival estimates were within the range expected for animals with a lifespan similar to that of Lost River suckers. Prior to full implementation of the remote PIT tag detection systems, which began in 2006, model-averaged estimates of $p$ for males were always below 0.2 and were double the estimates for females, which were never above 0.1. Estimates of $p$ were much higher for both sexes in 2006-2010, although estimates for males remained slightly higher than estimates for females. With the exception of 2010, estimates were about 0.93 for males with $125 \mathrm{kHz}$ tags and about 0.98 for males with $134 \mathrm{kHz}$ tags. Similarly, estimates were about 0.90 for females with $125 \mathrm{kHz}$ tags and about 0.97 for females with $134 \mathrm{kHz}$ tags. In 2010, estimates for both sexes and both tag types decreased to their lowest values since full implementation of the remote detection systems. Estimates of $p$ for males decreased by about 0.08 for both tag types and estimates for females decreased by about 0.14 for both tag types.

The encounter histories for the recruitment analysis included the same individuals as the survival analysis, but only included physical recaptures of those individuals. As a result, the density of the encounter histories and the size of the model set were much reduced. Model selection statistics were adjusted with a small overdispersion correction factor $(\hat{\mathbf{c}})$ of 1.19 , and indicated that the best model $\left(w_{i}=\right.$ $0.54)$ included only a single, time- and sex-constant parameter for seniority $(\gamma)$. The second best model $\left(w_{i}=0.29\right)$ included an effect of sex on $\gamma$, but the effect size on $\gamma$ due to sex was very small. The only other model in the set that had support was the model that constrained to be equal all annual $\gamma$ estimates that were on a boundary of 1.0 in the time-varying model. This model had little support $\left(w_{i}=0.16\right)$ and the constrained $\gamma$ parameter was still estimated on a boundary. Model-averaged estimates of $p$ were low and similar to estimates from the survival analysis for the years prior to implementation of the remote PIT tag detection systems (males: range $=0.06-0.16$, average $=0.11$; females: range $=0.02-0.06$, average $=0.04$ ). Model-averaged estimates of seniority indicated constant and very low levels of recruitment of new individuals into the adult spawning population. Estimates of seniority were higher than estimates of apparent survival in every year between 2002 and 2009, so derived estimates of population rate of change $(\lambda)$ were always less than 1.0 (fig. 7). Compounding the eight $\lambda$ estimates indicates that the abundance of female LRS in this subpopulation decreased by 29 percent $\left(\Delta_{t}=0.71\right)$ and the abundance of male LRS decreased by nearly 50 percent $\left(\Delta_{t}=0.51\right)$ through 2010 (fig. 8).

The fork length data collected over the last 13 years at the lakeshore spawning sites suggest that this subpopulation is comprised almost entirely of similarly sized individuals growing through time, with virtually no evidence of recruitment. Therefore, we consider the overall estimates of population 
decline based on derived $\lambda$ estimates to be lower bounds; that is, the declines may be more substantial than these estimates indicate. Indeed, the length data show that very few individuals of either sex collected since 1999 could be considered new recruits to the spawning population (fig. 9). A difference of a few percent in estimates of $\gamma$ seems trivial, but such differences can be important in terms of the overall $\Delta_{t}$ when compounded across 8 years. Therefore, we calculated what we consider to be upper bounds on the overall declines by assuming $\gamma$ to be 1.0 in all years $(\lambda=\Phi)$. These calculations indicate that the decline for females could be as much as 44 percent $\left(\Delta_{t}=0.56\right)$ and the decline for males could be as much as 60 percent $\left(\Delta_{t}=0.40\right.$; fig. 8$)$.

The time series of fork length data presented in Janney and others (2008) included data back to 1987 and showed that this subpopulation "turned over" during the early to mid-1990s. Prior to 1990, the subpopulation was rather homogeneous and was composed of relatively old, large individuals (males about 650 mm FL; females about 725 mm FL). Recruitment in the late 1980s to early 1990s, coupled with substantial losses of adults in large fish die-offs in 1995, 1996, and 1997, resulted in relatively young and small populations in the late 1990s and early 2000s. It appears that this subpopulation is now composed of a subset of the same individuals that were present in the early 2000s. Over the most recent decade, both sexes grew at consistent rates across years, with females adding about $11.5 \mathrm{~mm}$ FL per year and males about $9.3 \mathrm{~mm}$ FL per year (fig. 9). At present, the median fork length of males is 644 $\mathrm{mm}$ and the median fork length of females is $704 \mathrm{~mm}$, and individuals of both sexes show relatively little variability in size.

Williamson and Sprague River Spawning Subpopulation

From 2000 to 2010, we captured, tagged, and released 9,814 female and 6,465 male Lost River suckers in the Williamson River or the Sprague River. Excluding re-encounters in the year of tagging, we subsequently recaptured or remotely detected 8,345 (85 percent) of the females and 5,163 (80 percent) of the males on at least one occasion through 2011. An additional 3,274 females and 2,535 males from this subpopulation that were captured and tagged previously or elsewhere and then reencountered in one of the rivers between 2000 and 2010 also were included in the survival analysis. Almost all of these additional individuals were fish originally captured, tagged, and released at prespawn staging areas in the lake.

Model selection statistics for the 35 CJS models fitted to the encounter histories for this subpopulation indicated that the most parameterized model received all of the support $\left(w_{i}=1.00\right.$; table 4). The model included separate survival $(\Phi)$ parameters for each sex in each year, separate re-encounter probabilities $(p)$ for each sex in each year, and separate tag type effects on $p$ for each sex in year from 2006 to 2011. Because of the unequivocal support for the top model in model selection, model-averaged parameter estimates were the same as those from the top model. Estimates of $\Phi$ showed that survival varied over time for this subpopulation more than for the lakeshore spawning LRS (fig. 10). Survival of both sexes in 2000 was low, with female survival (0.82) higher than that for males (0.68). The estimates for males in 2005 and both sexes in 2001 and 2004 were on the boundary at 1.0, indicating estimability problems. Given the precision of the remaining estimates, survival for both sexes was high and similar to each other in 2002, 2003, and 2007-2009. Survival of females in 2006 was similar to the other years, but male survival was substantially lower in that year. With the exceptions of the year 2000 and males in 2006, survival of LRS spawning in the lake tributaries was similar to estimates from the lakeshore spawning subpopulation. In 2001-2004, prior to use of the remote PIT tag detection systems, estimates of $p$ for males and females were similar and varied between 0.02 and 0.07 . In 2005, the remote antennas in the traps at the Williamson River weir raised the estimates for both sexes to about 0.45 . Estimates of $p$ for both tag types were lower in $2006(0.17-0.35)$ because high flows compromised the detection 
efficiency of the antennas in the traps. With the exception of 2008, estimates of $p$ from 2007 to 2010 were similar to 2005 (about 0.45) for both males and females tagged with $125 \mathrm{kHz}$ PIT tags. In 2008, estimates decreased to 0.21 for males and 0.26 for females because of a loss of detection capabilities at the downstream weir trap caused by debris, as well as relatively high flows in general (but not as high as 2006). Finally, estimates of $p$ for males and females tagged with $134 \mathrm{kHz}$ tags were similar in 20072010, ranging between 0.90 and 0.95 . Re-encounter probabilities for fish tagged with $134 \mathrm{kHz}$ tags were less variable because more of the remote detection systems in the tributaries could detect those tags, particularly the river-wide array just upstream of the weir that was first installed in 2007. In contrast, the only systems that could detect the $125 \mathrm{kHz}$ tags were the antennas in the weir and the fish ladder at Chiloquin Dam. The antennas in the weir provided all detections for $125 \mathrm{kHz}$ tags following the removal of the dam in fall 2008.

The encounter histories for the recruitment analysis were handled in the same way as for the lakeshore spawning subpopulation. Model selection statistics were adjusted with a $\hat{c}$ value of 1.61 . The best model, which accounted for nearly one-half of the weight in the model set $\left(w_{i}=0.46\right)$, constrained the years in which seniority was estimated on a boundary (1.0) from the time varying model and allowed the other estimates to vary by time but not by sex. This model also included an additive effect of sex and year on recapture probability $(p)$. The second best model $\left(w_{i}=0.26\right)$ included the same structure on $\gamma$, but no additive sex effect on $p$. The third best model $\left(w_{i}=0.25\right)$ included a time and additive sex effect on both $\gamma$ and $p$. Model-averaged estimates of $p$ were low and similar between males and females, ranging between 0.02 and 0.13 with an average of 0.05 .

All of the models in the set that received any support included effects that showed some temporal variation in seniority. However, four of the nine individual $\gamma$ estimates (2002, 2004, 2005, 2007) in these models were estimated on the boundary at 1.0, even in models in which they were constrained to a single parameter. The model-averaged estimates of seniority indicate that in 2003, 2006, 2008, and 2009, the percentage of individuals of each sex in this subpopulation that were newly recruited to the spawning population ranged between 9 and 65 percent (fig. 10). However, the fork length data collected over the last 12 years show that few individuals small enough to be considered new recruits were captured in any of those years (fig. 11). An issue with sampling in the Chiloquin Dam fish ladder during the high flows of 2006 is responsible for the erroneous seniority estimates in that year (Hewitt and others, 2011). The low estimates of seniority in 2003, 2008, and 2009 are likely biased by a combination of factors related to the difficulty in monitoring this subpopulation by capture-recapture. We return to this issue in the section, "Discussion," but note here that we view these low seniority estimates with skepticism. Although the estimates of $\gamma$ for one-half of the years were on the boundary at 1.0 , which to some extent indicates problems with estimation, the length data suggest that it is entirely reasonable that there was virtually no recruitment of new individuals in those years. Furthermore, even if some new recruits entered the spawning population in some years, the small $\gamma$ estimates that indicate large recruitment events in 2003 and 2008 contrast sharply with the length data. Therefore, we regard the estimates of $\lambda$ for those years and the recent increasing trend in abundance that they imply as improbable (fig. 12). Rather, the overall trend in abundance probably is better characterized (if somewhat pessimistically) by assuming that no recruitment occurred in any year between 2002 and $2009(\gamma=1.0, \lambda=\Phi)$. Calculated in this way, the abundance of females in this subpopulation may have decreased by as much as 41 percent $\left(\Delta_{t}=0.59\right)$ and the abundance of males may have decreased by as much as 49 percent $\left(\Delta_{t}=0.51\right)$ through 2010 (fig. 12).

The time series of fork length data provided in Janney and others (2008) showed that river spawning LRS went through a demographic transition similar to that experienced by lakeshore spawning LRS. In the mid-1980s, this subpopulation was rather homogeneous and was composed of 
relatively old, large individuals (males about $620 \mathrm{~mm}$ FL; females about $675 \mathrm{~mm}$ FL), although somewhat smaller than individuals in the lakeshore spawning subpopulation. As a result of recruitment in the late 1980s to early 1990s, and losses of adults in fish die-offs in 1995, 1996, and 1997, the subpopulation was composed of relatively young and small individuals by the late 1990s. A subset of those individuals apparently now makes up the vast majority of the current spawning population. Over the most recent decade, both sexes grew at relatively consistent rates across years, with females adding about $10.3 \mathrm{~mm}$ FL per year and males about $7.5 \mathrm{~mm}$ FL per year (fig. 11). At present, the median fork length of males is $608 \mathrm{~mm}$ and the median fork length of females is $661 \mathrm{~mm}$. Individuals of both sexes show relatively little variability in size, and although some small fish collected at pre-spawn staging areas are evident in some years (for example, females in 2004 and 2010), these smaller fish never make up a large portion of the sample.

\section{Shortnose Suckers}

\section{Catch Summary and Run Timing for 2011}

Trammel net sampling at lakeshore springs captured three individual shortnose suckers, one of which had been tagged prior to the 2011 sampling season (table 1). Both of the newly tagged individuals were detected on the remote PIT tag antenna array upstream of the Williamson River weir within a week of being captured at the springs, and neither of them was detected on the remote antennas at the lakeshore springs. In total, the remote PIT tag antennas at the lakeshore springs detected 39 individual SNS (table 2). The majority of detections occurred during April and May. Of the 39 individuals detected, 13 (33 percent) also were detected in the Williamson River or Sprague River in 2011, and a total of 28 (72 percent) have been captured or detected in one of the rivers at some point in their history. For the lakeshore springs as a whole, only 1 of the 39 SNS detected on the remote PIT tag antennas also was captured in a trammel net.

We captured 1,600 shortnose suckers in trammel nets at pre-spawn staging areas, and 571 (36 percent) of these individuals had been tagged prior to the 2011 sampling season (table 1). The percentage of SNS captured at the staging areas that were previously tagged has increased rather steadily over the last 9 years, but the increase of 8 percent between 2010 and 2011 is larger than any annual increase since monitoring began. Of the PIT-tagged SNS captured at the staging areas, 72 percent were subsequently captured or detected somewhere in the Williamson River or Sprague River. Only four individuals were later captured or detected at the lakeshore springs and all four of those also were detected in the Williamson River.

A total of 181 SNS were captured in the upstream trap of the Williamson River weir, the lowest number captured since the weir was first installed in 2005 (table 1). The number of SNS captured in the weir trap has always been far fewer than for LRS, peaking at 367 in 2009 (versus a peak of 3,275 LRS, also in 2009). Of the 181 captured SNS, 58 (32 percent) had been tagged prior to the 2011 sampling season. The percentage of SNS captured in the weir that were previously tagged has increased steadily since 2005, and has been 3-4 percent smaller than the recapture percentage at the staging areas since 2009. Most individuals were captured between late April and mid-May. The remote PIT tag antennas at the weir combined to detect a total of 5,267 individual SNS (table 2). Detections began in mid-April, similar to LRS, but the two dominant peaks in detections of SNS coincided with the final two peaks in detections of LRS, in early and mid-May when water temperatures were approaching or exceeding 12 ${ }^{\circ} \mathrm{C}$ (fig. 13). 
The PIT tag antenna array in the Sprague River downstream of the Chiloquin Dam site detected 862 individual SNS between March 31 and June 20, but only one individual was detected before April 18 (table 2). The vast majority of detections occurred in early and mid-May when water temperatures were near or greater than $12^{\circ} \mathrm{C}$ (fig. 14). The antenna array upstream of the Chiloquin Dam site detected 483 SNS, and the antenna array at Braymill detected 19 SNS.

\section{Survival, Recruitment, and Size Composition}

Between 1999 and 2010, we captured, tagged, and released 9,900 female and 5,463 male shortnose suckers. Excluding re-encounters in the year of tagging, we subsequently recaptured or remotely detected 6,317 (64 percent) of the females and 3,128 (57 percent) of the males on at least one occasion through 2011. An additional 196 females and 146 males that were captured and tagged previously and then re-encountered between 1999 and 2010 also were included in the survival analysis.

Thirty-five CJS models were fitted to the SNS encounter histories to estimate apparent annual survival and re-encounter probabilities. The top model in the set had virtually all of the support (table $5)$. This model included separate $\Phi$ parameters for each sex in each year, as well as additive sex and year effects for $p$ and separate tag type effects for $p$ in each year from 2006 to 2011. Because of the unequivocal support for the top model in model selection, model-averaged parameter estimates were nearly identical to those from the top model. Estimates of $\Phi$ showed that survival was similar between the sexes in most years, but female survival was substantially higher than male survival in 2002 and 2006 (fig. 15). Survival for both sexes was especially low in 2001 and 2004. With the exception of those two years, survival estimates were similar to estimates for Lost River suckers and were within the range expected for animals with a lifespan similar to that of shortnose suckers. In 2000-2004, prior to use of the remote PIT tag detection systems, estimates of $p$ for males and females were similar and ranged between 0.03 and 0.12 . In 2005, the remote antennas in the traps at the Williamson River weir raised the estimates for both sexes to about 0.38. Estimates of $p$ for males and females tagged with $125 \mathrm{kHz}$ PIT tags decreased to 0.2 in 2006 because of the reduced efficiency of the antennas given the high flows in the river. For males and females tagged with $125 \mathrm{kHz}$ PIT tags, estimates of $p$ from 2007 to 2010 ranged between 0.21 and 0.39 (average $=0.29$ ), with a low in 2008 due to the loss of detection capabilities at the downstream weir trap caused by debris, as well as relatively high flows. Finally, estimates of $p$ for males and females tagged with $134 \mathrm{kHz}$ tags were about 0.4 in 2006 and then increased to about 0.91 (range $=0.88-0.94$ ) between 2007 and 2010. Re-encounter probabilities for fish tagged with $134 \mathrm{kHz}$ tags were less variable for the same reasons given for the river spawning subpopulation of LRS.

The encounter histories and modeling for the recruitment analysis were handled in the same way as for Lost River suckers. Model selection statistics were adjusted with a $\hat{c}$ value of 1.56 and indicated a fair degree of model selection uncertainty, with almost all of the support divided between the top three models in the set. The best model $\left(w_{i}=0.39\right)$ constrained seniority estimates to be the same for the years in which $\gamma$ was estimated on a boundary (1.0) from the time varying model (2001-2005 and 2007), and allowed the other $\gamma$ estimates to vary by time and sex. This model included a time effect but no sex effect on $p$. The second best model had nearly the same support in the model set $\left(w_{i}=0.36\right)$, and only differed from the top model in that it had both a time and sex effect on $p$. The only other model with substantial support $\left(w_{i}=0.21\right)$ was the same as the second best model except that it did not include a sex effect on $\gamma$. Model-averaged estimates of $p$ were low and similar between males and females, ranging between 0.02 and 0.13 with an average of 0.05 . Similar to river spawning LRS, all of the models in the set that received any support included effects that showed some temporal variation in seniority. However, six of the nine individual $\gamma$ estimates (2001-2005 and 2007) in these models were estimated on the boundary at 1.0, even in models in which they were constrained to a single parameter. 
The model-averaged estimates of seniority indicate that in 2006, 2008, and 2009, the percentage of individuals that were newly recruited to the spawning population ranged between 10 and 18 percent for females and between 11 and 27 percent for males. As with river spawning LRS, the low estimates of seniority in 2006 are likely biased by an issue with sampling in the Chiloquin Dam fish ladder (Hewitt and others, 2011). Derived estimates of lambda for 2008 and 2009 are imprecise and the confidence intervals broadly overlap 1.0, but the point estimates indicate some recruitment of new spawners, particularly for males in 2008 (fig. 15). However, the overall trend in spawning population size is down. Compounding the nine $\lambda$ estimates indicates that the abundance of female SNS decreased by 62 percent $\left(\Delta_{t}=0.38\right)$ and the abundance of male SNS decreased by 64 percent $\left(\Delta_{t}=0.36\right)$ through 2010 (fig. 16).

Similar to lakeshore spawning LRS, the fork length data collected over the last 12 years for SNS suggests that the population is comprised almost entirely of similarly sized individuals, with virtually no evidence of recruitment (fig. 17). This evidence contrasts with the seniority estimates for 2008 and 2009 that indicate recruitment of new spawners. Recruitment analyses for SNS share some of the difficulties with capture-recapture monitoring that was seen for river spawning LRS, although to a lesser degree. Again, we defer a full account of these issues to the section, "Discussion," but these issues lead us to conclude that the overall trend in spawning population size probably is more negative than indicated by the derived lambda estimates. As we have done for the LRS subpopulations, we calculated what we consider to be upper bounds on the overall declines by assuming $\gamma$ to be 1.0 in all years $(\lambda=\Phi)$. The decline for females could be as much as 76 percent $\left(\Delta_{t}=0.24\right)$ and the decline for males could be as much as 82 percent $\left(\Delta_{t}=0.18\right.$; fig. 16$)$.

The time series of fork length data provided in Janney and others (2008) included data back to 1984 and showed that the shortnose sucker population in Upper Klamath Lake went through a demographic transition similar to that for Lost River suckers. In the mid-1980s, the SNS population was rather homogeneous and was composed of relatively old and large individuals (males about 425 mm FL; females about $450 \mathrm{~mm} \mathrm{FL).} \mathrm{The} \mathrm{population} \mathrm{then} \mathrm{"turned} \mathrm{over"} \mathrm{as} \mathrm{a} \mathrm{result} \mathrm{of} \mathrm{recruitment} \mathrm{in} \mathrm{the} \mathrm{late}$ 1980s to early 1990s and losses of adults in fish die-offs in 1995, 1996, and 1997. The current population is mostly a subset of the individuals that were present in the late 1990s. Both sexes grew at consistent rates between 2000 and 2011, adding about 4 mm FL per year (fig. 17). However, both males and females appear not to have grown since 2009. The median fork length of each sex has been essentially the same for the last 3 years and is now similar to what it was in the mid-1980s (males about $428 \mathrm{~mm}$; females about $452 \mathrm{~mm}$ ). To investigate the apparent lack of growth further, we compared fork lengths of individual SNS captured in multiple years between 2009 and 2011. Individuals captured in 2009 and recaptured in 2010 had added $2.4 \mathrm{~mm} \mathrm{FL}$ on average (median $=2 \mathrm{~mm}$, range $=-9$ to $17 \mathrm{~mm}$ ), whereas individuals captured in 2010 and recaptured in 2011 had lost $0.3 \mathrm{~mm}$ FL on average (median = $0 \mathrm{~mm}$, range $=-10$ to $12 \mathrm{~mm}$ ). Finally, individuals captured in 2009 and recaptured in 2011 had added $1.7 \mathrm{~mm}$ FL per year on average (median $=1.5 \mathrm{~mm}$, range $=-5$ to $8 \mathrm{~mm}$ ). These results support the conclusion that growth of SNS in Upper Klamath Lake has dramatically slowed or stopped altogether by 2011. 


\section{Discussion}

A number of factors lead us to conclude that serious concern is warranted for the populations of Lost River suckers and shortnose suckers in Upper Klamath Lake, and that the current situation is most dire for SNS. Capture-recapture results and size composition data show that the abundance of both species has steadily declined since the early 2000s, continuing trends documented in Hewitt and others (2011). The SNS population has declined more than either subpopulation of LRS, but the abundances of both species probably have declined by more than 40 percent over the last decade. These declines primarily reflect a lack of recruitment of new individuals into the spawning populations, but capturerecapture estimates show that both species have experienced some years with relatively poor survival as well. The decline in abundance for SNS could be 75 percent or more since 2001, and SNS have experienced more years with poor survival than either subpopulation of LRS. All populations have shown high survival in the most recent 3 years for which we have estimates (2007-2009).

The vast majority of suckers in the lake were spawned in the early 1990s, meaning that most of the individuals of both species, but especially SNS, have been mature for many years and are now close to or beyond the average expected lifespan for the species. Although we do not know what the time course of senescence is for these species, fork length data from captured fish shows that growth in length has essentially stopped for SNS by 2011. Without some recruitment of new spawners, the decline in abundance for SNS may accelerate as more individuals approach the maximum life span and the overall mortality rate increases.

Despite these worrisome indicators, our monitoring shows that the abundance of both endangered suckers in Upper Klamath Lake is still at an order of magnitude that affords some protection from catastrophic mortality events, such as die-offs in the summer and fall caused by poor water quality (for example, Perkins and others, 2000). Over the course of a spawning season, total counts of PITtagged individuals that are either captured in trammel net sampling or detected by the remote PIT tag detection systems provide absolute minimum abundances for the two species. In 2011, we encountered more than 6,500 lakeshore spawning LRS, more than 16,500 river spawning LRS, and more than 6,000 SNS. We know that these numbers are not accurate minimum abundances because the recapture percentages from weir and trammel net sampling (table 1) show that a large proportion of fish in each population is not PIT-tagged. We can use the recapture percentages to adjust upwards the number of PIT-tagged fish that were encountered during a season (removing encounters of individuals that were first PIT-tagged in that season). As of the start of the 2011 sampling season, these calculations give revised minimum abundances of around 10,000 lakeshore spawning LRS, around 90,000 river spawning LRS, and around 11,000 SNS. These numbers provide a general sense of how many fish are in the spawning populations, but they are not estimates in any formal sense. They cannot be used to track changes in population size and should be used cautiously in any context for at least two major reasons. First, encounter probabilities are high because of the remote detection systems, but they are less than 1 , are variable through time, and vary among populations and between sexes and PIT tag types (125 vs. $134 \mathrm{kHz}$ ). Second, the recapture percentages from the weir and trammel net sampling may not apply to the entire populations because of the heterogeneity in encounter probabilities and the fact that we do not sample the spawning populations in a randomized design. Formal estimation of abundance requires that models account for variability and heterogeneity in encounter probabilities, and this is typically the Achilles heel of abundance estimation for large fish populations (see Hewitt and others, 2010 and references therein).

Instead of estimating abundance directly, our monitoring program focuses on estimating survival and seniority parameters that can track changes in abundance through time and are robust to issues associated with encounter probabilities. However, modeling and estimation of seniority and population 
rate of change are still challenging for populations that are relatively large, such as river spawning LRS. A major reason is that the detections from the remote PIT tag antennas cannot be used in estimating these parameters, and recapture probabilities based on weir and trammel net sampling are small (less than 0.16). Modeling of seniority and population rate of change has been more successful for lakeshore spawning LRS because recruitment has been trivial since our monitoring began and because the nature of the spawning aggregations at the springs makes it possible to sample a large proportion of the subpopulation; more than 50 percent of the subpopulation is now PIT-tagged.

A number of other factors complicate the estimation and interpretation of seniority and population rate of change for river spawning LRS. Heterogeneity in encounter probabilities is the most troublesome issue, and is indicated by the goodness of fit of the global model for the seniority analysis as well as the difference in recapture percentages between the sampling at the pre-spawning staging areas and the Williamson River weir. Some of the goodness-of-fit tests for the global model indicated large deviations from expected values for each sex in some years, but without any apparent pattern. We suspect that this occurs because groups of fish associate during the spawning season and either avoid capture or are captured together. Indeed, we see this happen at the weir on some days when large numbers of LRS are captured but few of them have PIT tags. Heterogeneity on the individual level also is indicated by the difference in the percentage of recaptures between the trammel net sampling at the pre-spawning staging areas and captures in the weir trap. The recapture percentage at staging areas has always been greater than at the weir, and was greater by 8-10 percent in the last 2 years. If these sampling efforts target the same statistical population, differences of this magnitude would be unlikely. We suspect that the observed differences are due in part to heterogeneity in capture probabilities at the weir, which is due at least in part to the fact that the weir was installed in 2005 and has operated as a method of capture for river spawning LRS for only 6 years (the weir was ineffective during the high flows in 2006). Although we typically capture thousands of individuals each year, this number represents a relatively small proportion of the total spawning population. Another possibility is that some river spawning LRS do not aggregate at staging areas prior to spawning, or aggregate somewhere else.

With regard to modeling and estimation, heterogeneity in encounter probabilities leads to apparently biased estimates of seniority for river spawning LRS. Low estimates of seniority, particularly in 2003 and 2008, indicate substantial recruitment of new spawners. Although some recruitment is possible, the magnitude of recruitment suggested by such low estimates of seniority contrasts strongly with size composition data. We suspect that the fish the model interprets as new recruits to the spawning population are rather just individuals, or groups of individuals, that have avoided capture by the monitoring program for some other reason. We expect that such issues with interpretation will resolve over time as more of the population is captured and PIT-tagged, although this could take many more years. Sampling effort at the weir can be increased, but there are logistical constraints to the amount of time the trap can be closed during the spawning runs. We note that the same issues apply to the SNS population, but to a lesser extent. The SNS population is much smaller than the river spawning subpopulation of LRS, we have captured and tagged a larger proportion of the SNS population, and modeling and estimation indicate a smaller amount of heterogeneity for SNS than for river spawning LRS. Although the seniority estimates for SNS in 2008 and 2009 appear to be erroneously small, the derived rates of change in abundance have large confidence intervals that appropriately reflect their lack of precision. Furthermore, the overall trend in abundance is not affected by these estimates nearly as much as for river spawning LRS. 
The low lake elevation during the spawning season in 2010 resulted in much less water over the spawning habitat at the lakeshore springs, and may have had a negative effect on Lost River sucker spawning at that location. Following the drought year of 2009, the lake elevation in 2010 during spawning was around $4140.5 \mathrm{ft}$, which is more than $2 \mathrm{ft}$ lower than average over the last decade. The encounter probabilities for LRS at the lakeshore springs in 2010 were lower than they have been in any year since we began full implementation of the remote PIT tag detection systems in 2006. Decreases in the encounter probabilities indicate that about 8 percent of males and 14 percent of females were absent from the spawning aggregations subject to our sampling, meaning that fish either skipped spawning in 2010, spawned farther offshore where we could not detect them, or spawned somewhere else entirely.

We consider it unlikely that fish spawned at some other location because of the strong fidelity that LRS show to their spawning areas, and because we did not detect any increase in the number of LRS straying from the lakeshore springs to the Williamson River in 2010.

\section{Acknowledgments}

We thank Mark Johnson, Amari Dolan-Caret, Justin Koller, Todd Perry, Travis Ciotti, Elizabeth Ng, Brittany Thompson, Nick Miller, Ed May, Ryan Braham, Nate Lewis, and all members of the past field crews for their dedication to the project and their assistance with data curation and management. We thank Josh Rasmussen (U.S. Fish and Wildlife Service) and Jared Bottcher (Klamath Basin Rangeland Trust) for reviewing drafts of this report. Funding was provided by the Bureau of Reclamation, U.S. Department of Interior (Interagency Agreement 06AA204052), and USGS. Funding was provided by Reclamation as part of its mission to manage, develop, and protect water and related resources in an environmentally and economically sound manner in the interest of the American public.

\section{References Cited}

Anderson, D.R., Burnham, K.P., and White, G.C., 1994, AIC model selection in overdispersed capturerecapture data: Ecology, v. 75, p. 1,780-1,793.

Anthony, R.G., Forsman, E.D., Franklin, A.B., Anderson, D.R., Burnham, K.P., White, G.C., Schwarz, C.J., Nichols, J.D., Hines, J.E., Olson, G.S., Ackers, S.H., Andrews, L.S., Biswell, B.L., Carlson, P.C., Diller, L.V., Dugger, K.M., Fehring, K.E., Fleming, T.L., Gerhardt, R.P., Gremel, S.A., Gutiérrez, R.J., Happe, P.J., Herter, D.R., Higley, J.M., Horn, R.B., Irwin, L.L., Loschl, P.J., Reid, J.A., and Sovern, S.G., 2006, Status and trends in demography of northern spotted owls, 1985-2003: Wildlife Monographs, v. 163, 48 p.

Banish, N.P., Adams, B.J., Shively, R.S., Mazur, M.M., Beauchamp, D.A., and Wood, T.M., 2009, Distribution and habitat associations of radio-tagged adult Lost River suckers and shortnose suckers in Upper Klamath Lake, Oregon: Transactions of the American Fisheries Society, v. 138, p. 153-168.

Bradbury, J.P., Colman, S.M., and Reynolds, R.L., 2004, The history of recent limnological changes and human impact on Upper Klamath Lake, Oregon: Journal of Paleolimnology, v. 31, p. 151-165.

Buckland, S.T., Burnham, K.P., and Augustin, N.H., 1997, Model selection: an integral part of inference: Biometrics, v. 53, p. 603-618.

Burnham, K.P., and Anderson, D.R., 2002, Model selection and multimodel inference-A practical information-theoretic approach, 2nd ed.: Springer, New York, 488 p.

Choquet, R., Lebreton, J.D., Gimenez, O., Reboulet, A.M., and Pradel, R., 2009, U-CARE: utilities for performing goodness of fit tests and manipulating CApture-REcapture data: Ecography, v. 32, p. 1,071-1,074. 
Cooch, E., and White, G., editors, 2010, Program MARK-A gentle introduction, 9th ed.: accessed May 16, 2011, at http://www.phidot.org/software/mark/docs/book/.

Cooperman, M., and Markle, D.F., 2003, Rapid out-migration of Lost River and shortnose sucker larvae from in-river spawning beds to in-lake rearing grounds: Transactions of the American Fisheries Society, v. 132, p. 1,138-1,153.

Eilers, J.M., Kann, J., Cornett, J., Moser, K., and St. Amand, A., 2004, Paleolimnological evidence of change in a shallow, hypereutrophic lake: Upper Klamath Lake, Oregon, USA: Hydrobiologia, v. 520, p. 7-18.

Franklin, A.B., 2001, Exploring ecological relationships in survival and estimating rates of population change using Program MARK, in Field, R., Warren, R.J., Okarma, H., and Sievert, P.R., eds., Proceedings of the Second International Wildlife Management Congress: The Wildlife Society, Bethesda, Maryland, p. 350-356.

Hewitt, D.A., Janney, E.C., Hayes, B.S., and Shively, R.S., 2010, Improving inferences from fisheries capture-recapture studies through remote detection of PIT tags: Fisheries, v. 35, p. 217-231.

Hewitt, D.A., Hayes, B.S., Janney, E.C., Harris, A.C., Koller, J.P., and Johnson, M.A., 2011, Demographics and run timing of adult Lost River (Deltistes luxatus) and shortnose (Chasmistes brevirostris) suckers in Upper Klamath Lake, Oregon, 2009: U.S. Geological Survey Open-File Report 2011-1088, 38 p. (Also available at http://pubs.usgs.gov/of/2011/1088/.)

Hines, J.E., and Nichols, J.D., 2002, Investigations of potential bias in the estimation of $\lambda$ using Pradel's (1996) model for capture-recapture data: Journal of Applied Statistics, v. 29, p. 573-587.

Janney, E.C., Barry, P.M., Hayes, B.S., Shively, R.S., and Scott, A., 2006, Demographic analysis of adult Lost River suckers and shortnose suckers in Upper Klamath Lake and its tributaries, Oregon: Report to the Klamath Area Office of the Bureau of Reclamation, U.S. Geological Survey, Klamath Falls Field Station, Oregon, 42 p.

Janney, E.C., Shively, R.S., Hayes, B.S., Barry, P.M., and Perkins, D., 2008, Demographic analysis of Lost River sucker and shortnose sucker populations in Upper Klamath Lake, Oregon: Transactions of the American Fisheries Society, v. 137, p. 1,812-1,825.

Janney, E.C., Hayes, B.S., Hewitt, D.A., Barry, P.M., Scott, A., Koller, J., Johnson, M., and Blackwood, G., 2009, Demographics and 2008 run timing of adult Lost River (Deltistes luxatus) and shortnose (Chasmistes brevirostris) suckers in Upper Klamath Lake, Oregon, 2008: U.S. Geological Survey Open-File Report 2009-1183, 32 p. (Also available at http://pubs.usgs.gov/of/2009/1183/.)

Kann, J., and Smith, V.H., 1999, Estimating the probability of exceeding elevated pH values critical to fish populations in a hypereutrophic lake: Canadian Journal of Fisheries and Aquatic Sciences, v. 56, p. 2,262-2,270.

Laake, J., 2010, RMark: R code for MARK analysis, version 1.9.9: accessed May 16, 2011, at http://www.phidot.org/software/mark/rmark/.

Laake, J., and Rexstad, E., 2010, RMark-an alternative approach to building linear models in MARK, Appendix C in Cooch, E., and White, G., eds., Program MARK-A gentle introduction, 9th ed.

Lindenberg, M.K., Hoilman, G., and Wood, T.M., 2009, Water quality conditions in Upper Klamath and Agency Lakes, Oregon, 2006: U.S. Geological Survey Scientific Investigations Report 20085201, 54 p. (Also available at http://pubs.usgs.gov/sir/2008/5201/.)

Markle, D.F., and Cooperman, M.S., 2002, Relationships between Lost River and shortnose sucker biology and management of Upper Klamath Lake, in Braunworth, W.S., Jr., Welch, T., and Hathaway, R., eds., Water allocation in the Klamath Reclamation Project, 2001: Corvallis, Oregon State University Extension Service, Special Report 1037, p. 93-117.

Moyle, P.B., 2002, Inland fishes of California: Berkeley, University of California Press, 502 p. 
National Research Council, 2004, Endangered and threatened fishes in the Klamath River Basin-Causes of decline and strategies for recovery: Washington, D.C., The National Academies Press, 397 p.

Nichols, J.D., 2005, Modern open-population capture-recapture models, in Amstrup, S.C., McDonald, T.L., and Manly, B.F.J., eds., Handbook of capture-recapture analysis: Princeton, New Jersey, Princeton University Press, p. 88-123.

Nichols, J.D., and Hines, J.E., 2002, Approaches for the direct estimation of $\lambda$, and demographic contributions to $\lambda$, using capture-recapture data: Journal of Applied Statistics, v. 29, p. 539-568.

Otis, D.L., Burnham, K.P., White, G.C., and Anderson, D.R., 1978, Statistical inference from capture data on closed animal populations: Wildlife Monographs, v. 62, 135 p.

Perkins, D.L., Kann, J., and Scoppettone, G.G., 2000, The role of poor water quality and fish kills in the decline of endangered Lost River and shortnose suckers in Upper Klamath Lake: U.S. Geological Survey final report to the Bureau of Reclamation, Contract 4-AA-29-12160, Klamath Falls, Oregon, 39 p.

Pollock, K.H., Yoshizaki, J., Fabrizio, M.C., and Schram, S.T., 2007, Factors affecting survival rates of a recovering lake trout population estimated by mark-recapture in Lake Superior, 1969-1996:

Transactions of the American Fisheries Society, v. 136, p. 185-194.

Pradel, R., 1996, Utilization of capture-mark-recapture for the study of recruitment and population growth rate: Biometrics, v. 52, p. 703-709.

R Development Core Team, 2010, R: a language and environment for statistical computing: R Foundation for Statistical Computing, Vienna, Austria: accessed May 16, 2011, at http://www.Rproject.org/.

Reiser, D.W., Loftus, M., Chapin, D., Jeanes, E., and Oliver, K., 2001, Effects of water quality and lake level on the biology and habitat of selected fish species in Upper Klamath Lake: R2 Resource Consultants, Inc. report to the Bureau of Indian Affairs, Portland, Oregon, 147 p.

Scoppettone, G.G., and Vinyard, G., 1991, Life history and management of four endangered lacustrine suckers, in Minckley, W.L., and Deacon, J.E., eds., Battle against extinction-Native fish management in the American West: Tucson, The University of Arizona Press, p. 359-377.

Terwilliger, M.R., Reece, T., and Markle, D.F., 2010, Historic and recent age structure and growth of endangered Lost River and shortnose suckers in Upper Klamath Lake, Oregon: Environmental Biology of Fishes, v. 89, p. 239-252.

Tobin, J.H., 1994, Construction and performance of a portable resistance board weir for counting migrating adult salmon in rivers: Alaska Fisheries Technical Report Number 22, U.S. Fish and Wildlife Service, Kenai.

U.S. Fish and Wildlife Service, 1993, Lost River (Deltistes luxatus) and shortnose (Chasmistes brevirostris) sucker recovery plan: Portland, Oregon, 108 p.

White, G.C., and Burnham, K.P., 1999, Program MARK: survival rate estimation from populations of marked animals: Bird Study, v. 46 (Supplement), p. S120-S139.

Williams, B.K., Nichols, J.D., and Conroy, M.J., 2002, Analysis and management of animal populations: New York, Academic Press, 817 p.

Wood, T.M., Hoilman, G.R., and Lindenberg, M.K., 2006, Water-quality conditions in Upper Klamath Lake, Oregon, 2002-04: U.S. Geological Survey Scientific Investigations Report 2006-5209, 52 p. (Also available at http://pubs.usgs.gov/sir/2006/5209/.) 


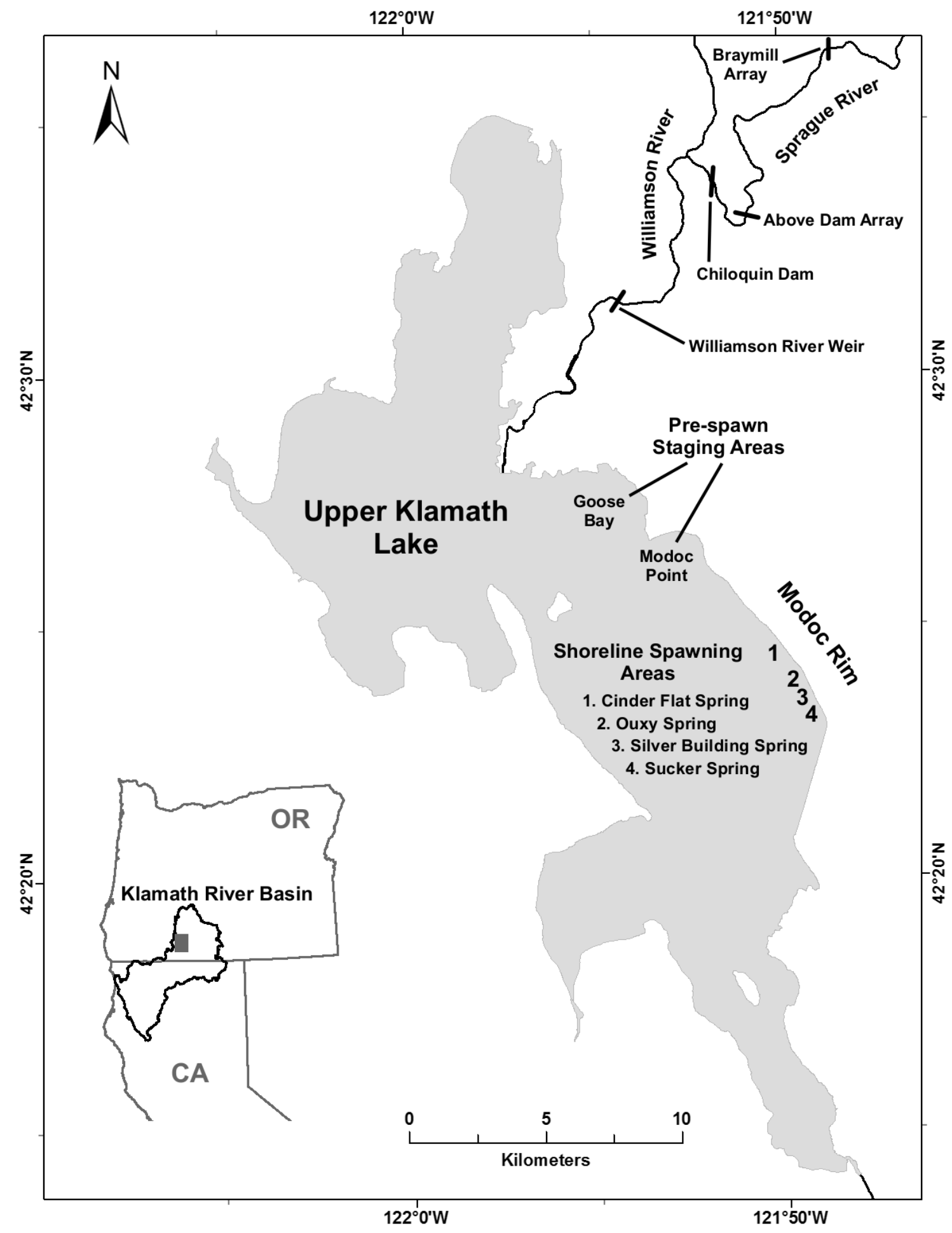

Figure 1. Map showing sampling locations for Lost River suckers and shortnose suckers in Upper Klamath Lake and its tributaries. The inset shows the Klamath River Basin and the location of Upper Klamath Lake in southcentral Oregon. 

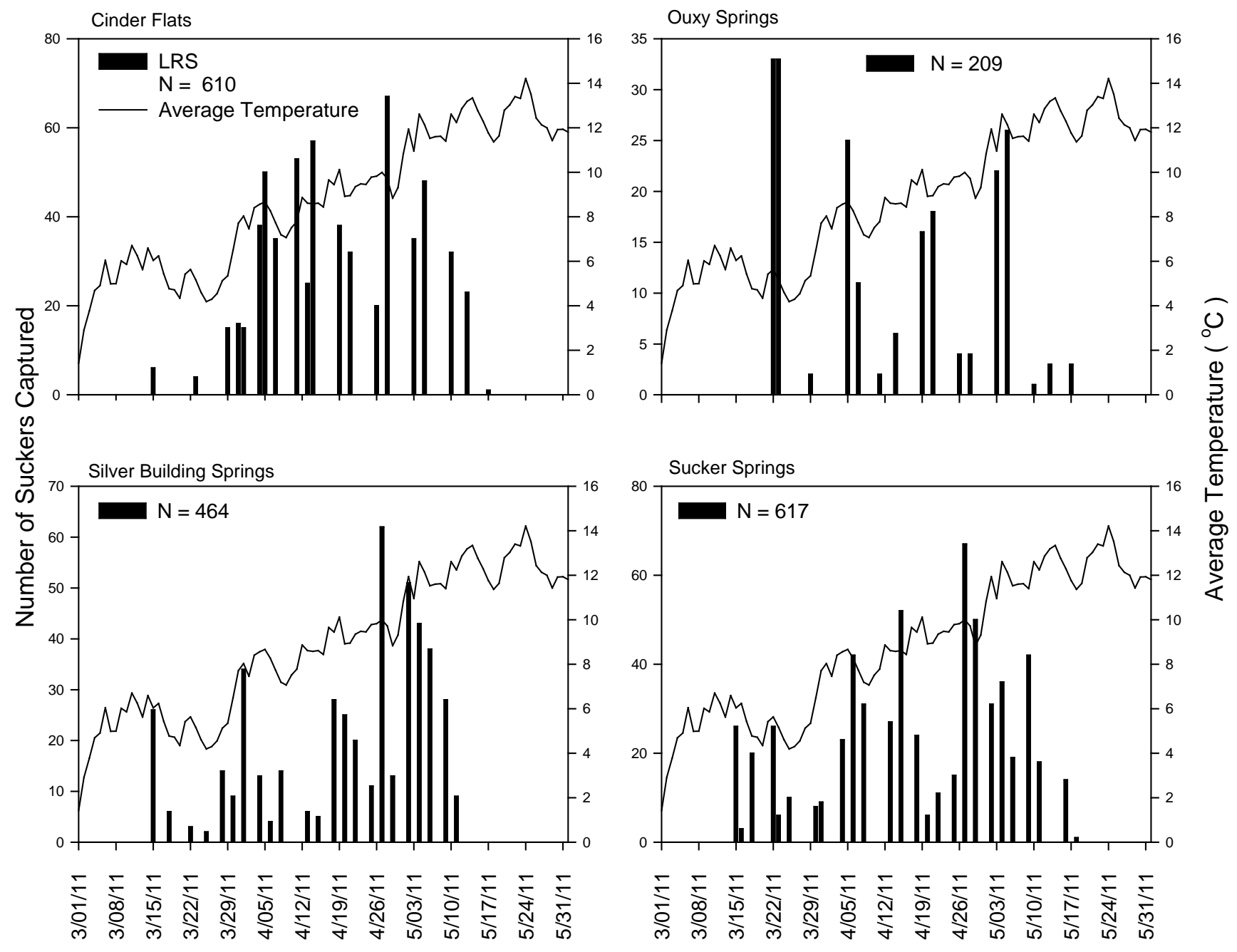

Date

Figure 2. Seasonality of trammel net captures of Lost River suckers at lakeshore springs in Upper Klamath Lake, Oregon, 2011. Average daily water temperature $\left({ }^{\circ} \mathrm{C}\right)$ is reported from a temperature logger that was placed just offshore away from spring influence near Cinder Flats. If fish were captured more than once at a given spring, only the first capture is included. Some fish were captured at multiple springs and are thus included in more than one plot. 


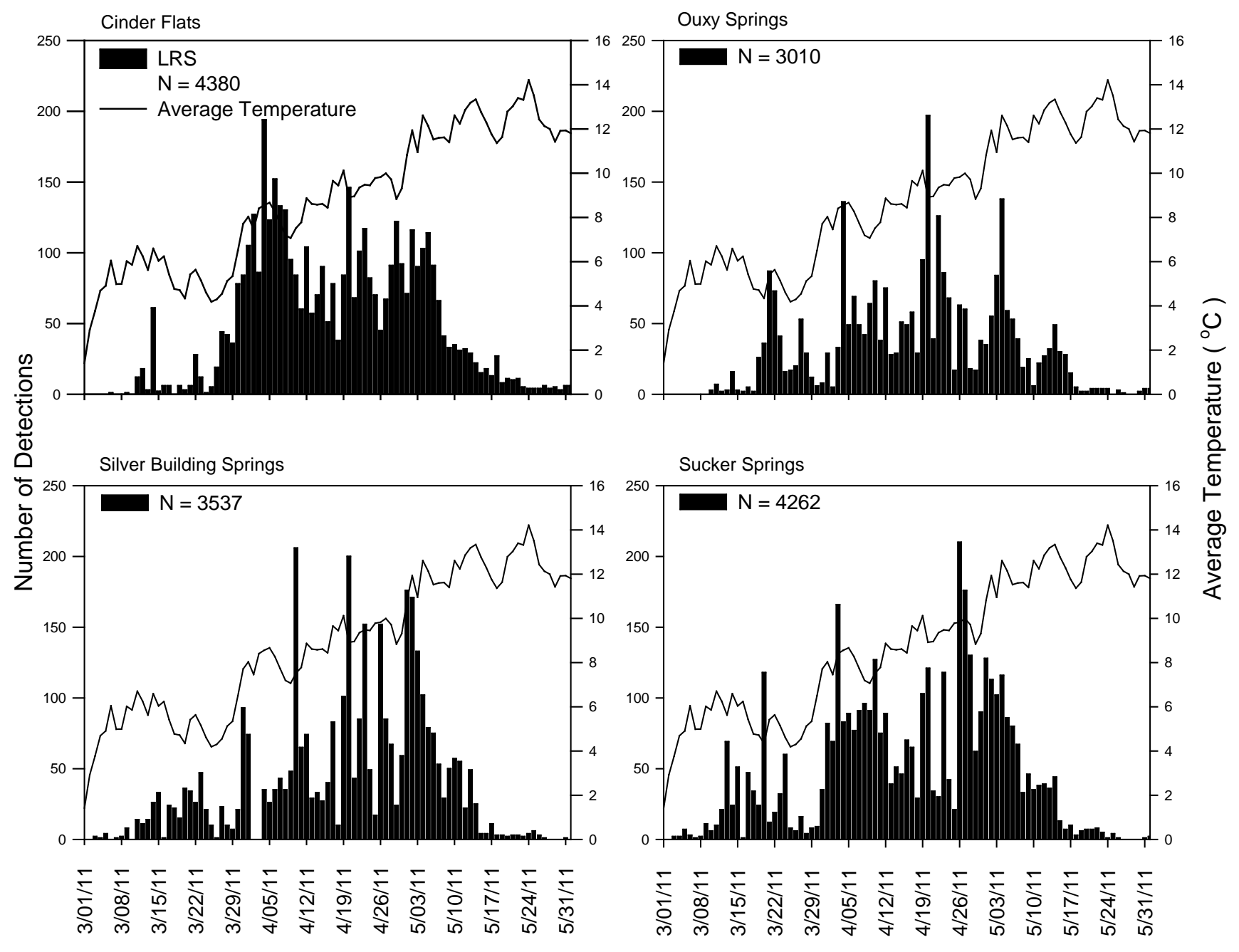

Date

Figure 3. Seasonality of detections of Lost River suckers on remote passive integrated transponder (PIT) tag antennas at lakeshore springs in Upper Klamath Lake, Oregon, 2011. Average daily water temperature $\left({ }^{\circ} \mathrm{C}\right)$ is reported from a temperature logger that was placed just offshore away from spring influence near Cinder Flats. If fish were detected more than once at a given spring, only the first detection is included. Some fish were detected at multiple springs and are thus included in more than one plot. 

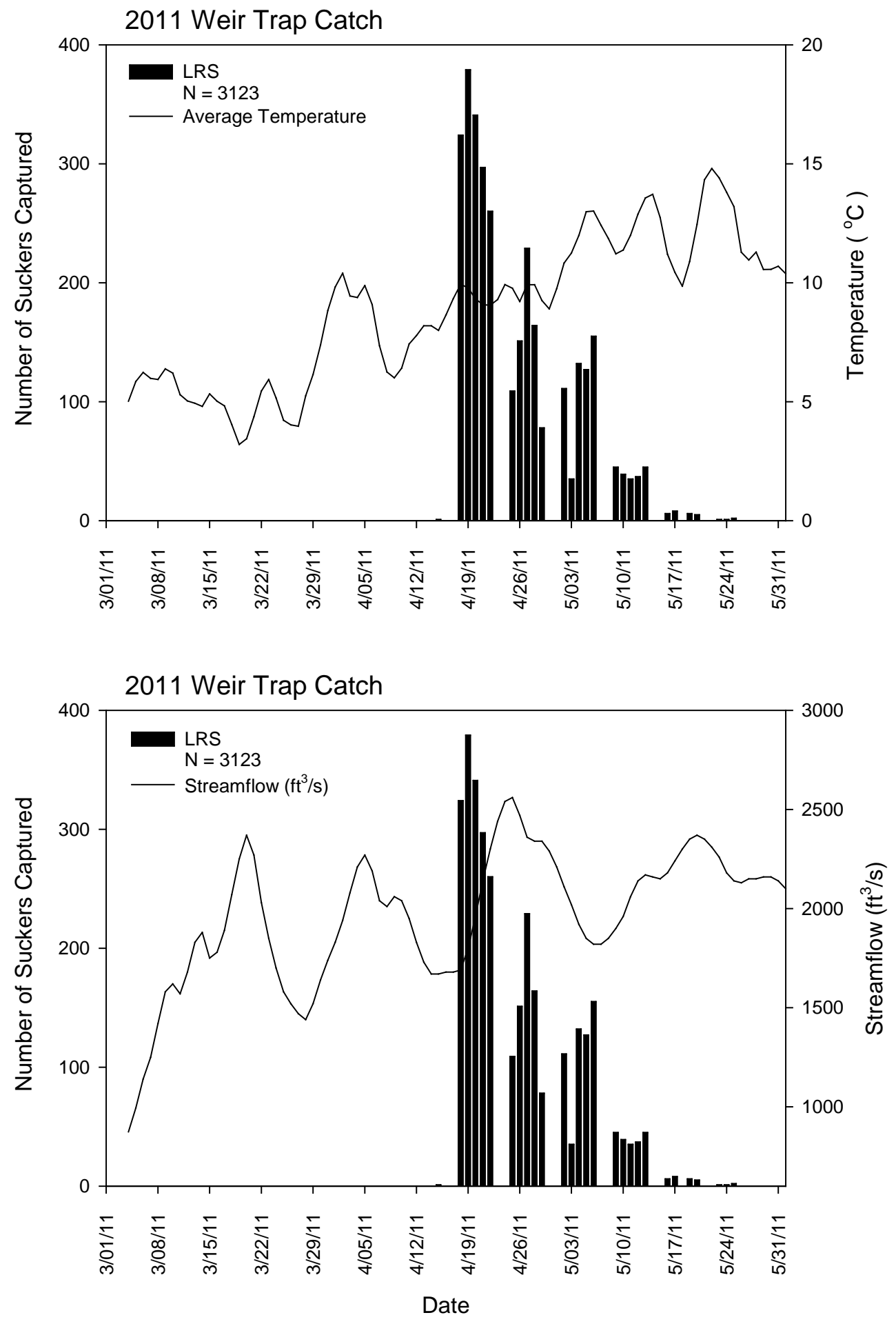

Figure 4. Seasonality of captures of Lost River suckers in the upstream trap of the Williamson River weir during 2011. If fish were captured more than once, only the first capture is included. Average daily water temperature $\left({ }^{\circ} \mathrm{C}\right)$ and streamflow (ft3/s) are reported from the USGS gage on the Williamson River downstream of the confluence with the Sprague River near Chiloquin, Oregon (11502500). 

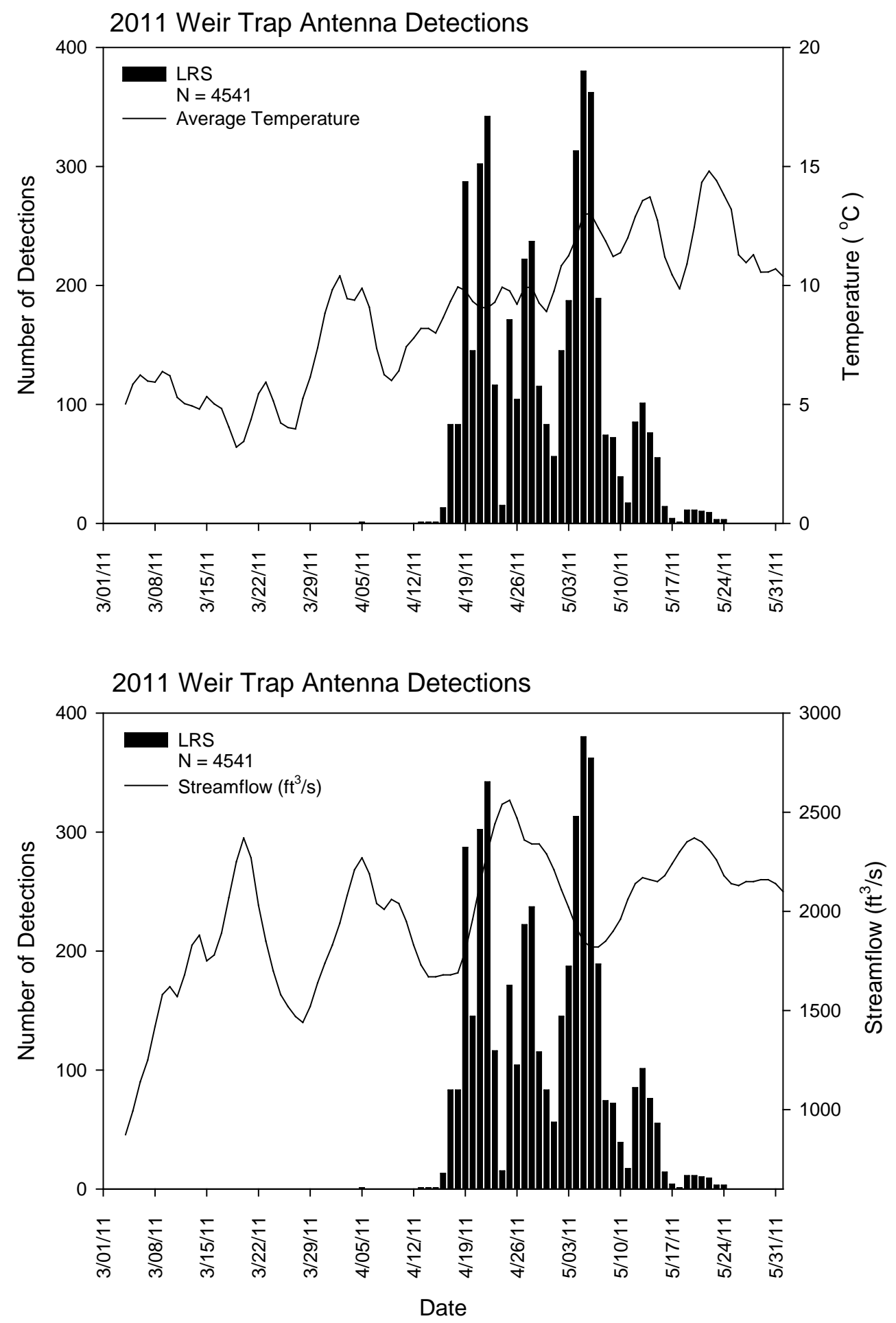

Figure 5. Seasonality of detections of Lost River suckers on the remote passive integrated transponder (PIT) tag antenna at the upstream trap of the Williamson River weir in 2011. If fish were detected more than once, only the first detection is included. Average daily water temperature $\left({ }^{\circ} \mathrm{C}\right)$ and streamflow $(\mathrm{ft} 3 / \mathrm{s})$ are reported from the USGS gage on the Williamson River downstream of the confluence with the Sprague River near Chiloquin, Oregon (11502500). 

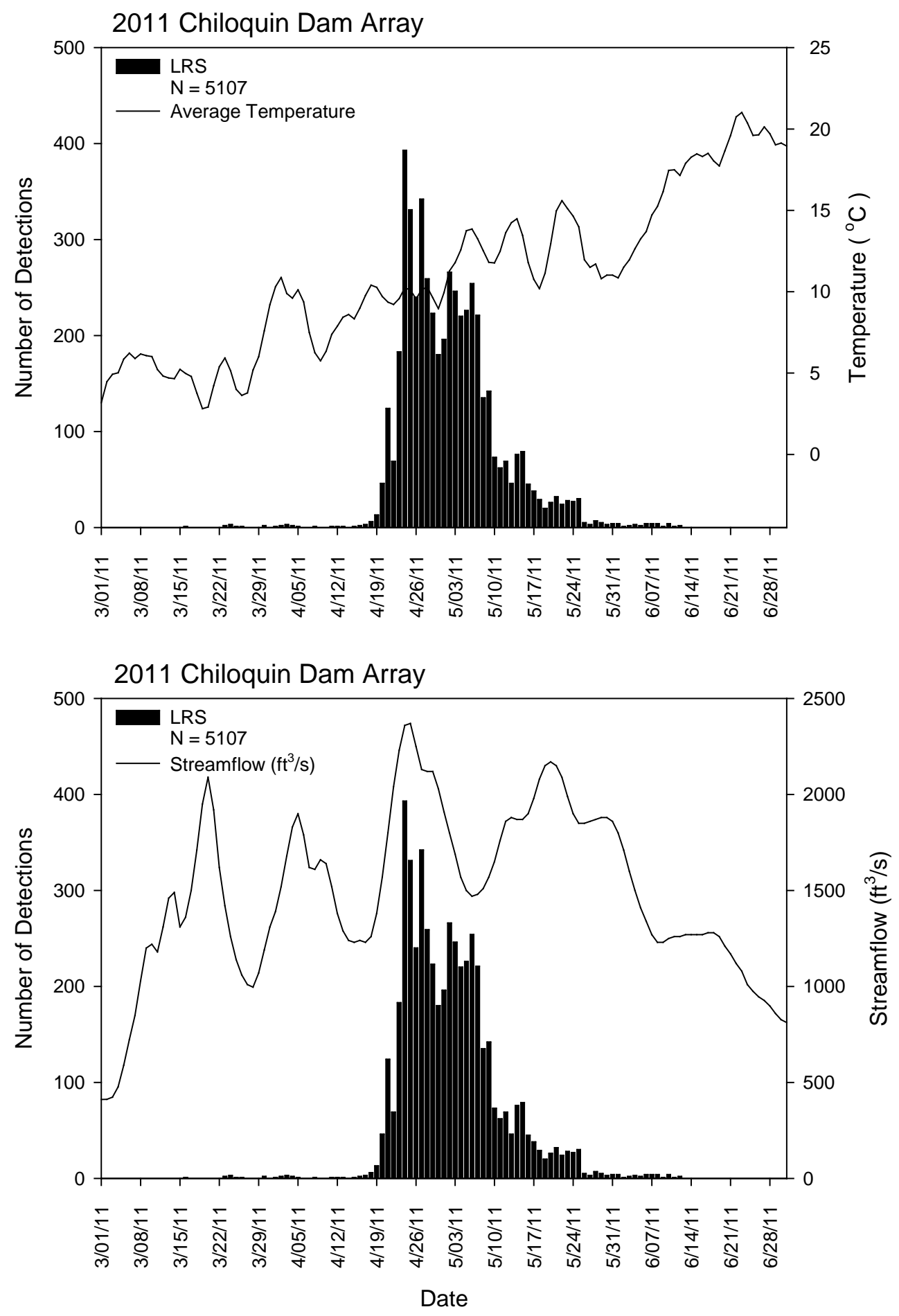

Figure 6. Seasonality of detections of Lost River suckers on the remote passive integrated transponder (PIT) tag antenna array across the Sprague River just downstream of the Chiloquin Dam site in 2011. If fish were detected more than once, only the first detection is included. Average daily water temperature $\left({ }^{\circ} \mathrm{C}\right)$ and streamflow $\left(\mathrm{ft}^{3} / \mathrm{s}\right)$ are reported from the USGS gage on the Sprague River upstream of the confluence with the Williamson River, upstream of Chiloquin, Oregon (11501000). 


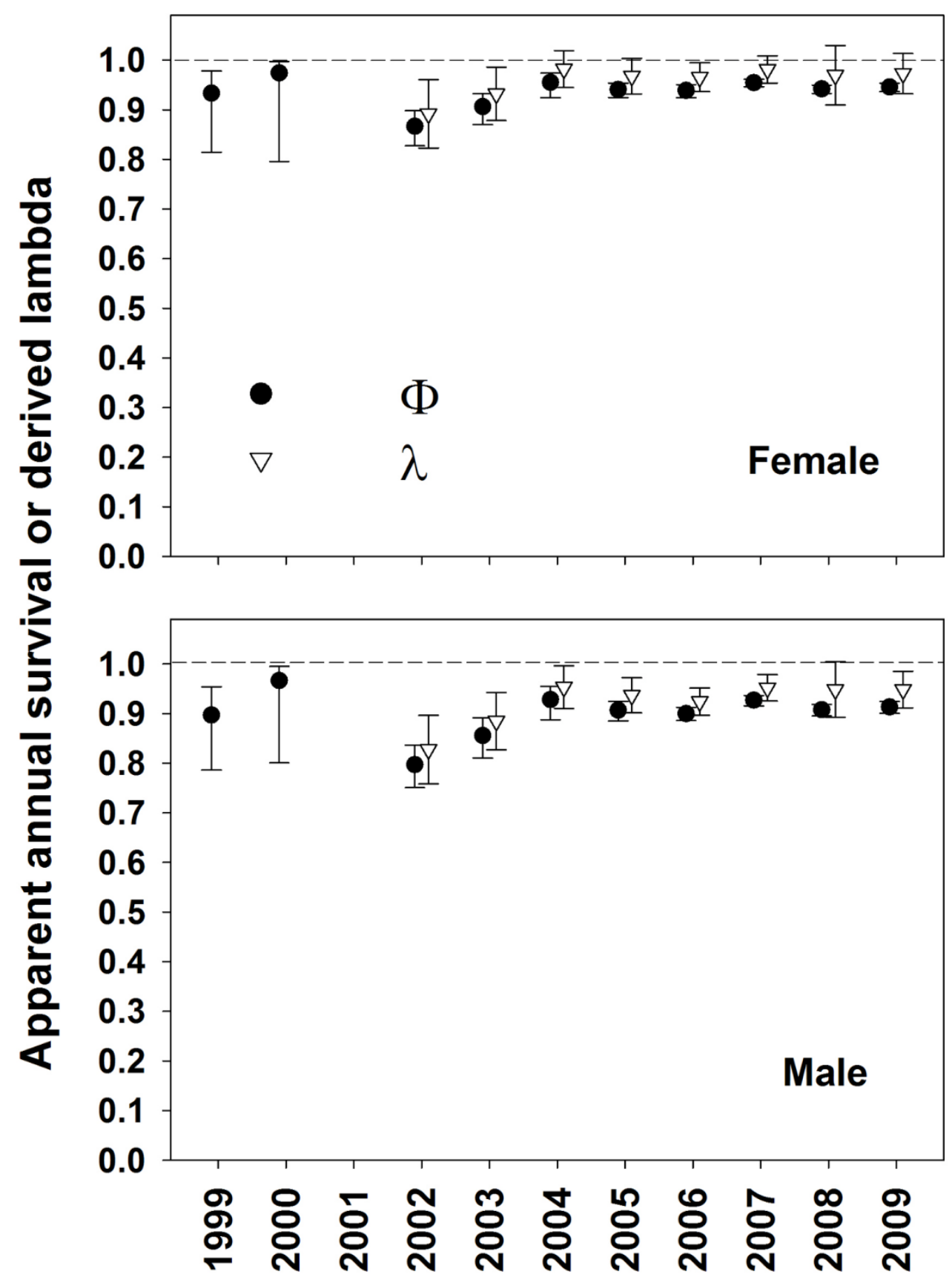

Figure 7. Model-averaged estimates of apparent annual survival probability $(\Phi)$ and derived population rate of change $(\lambda)$ with 95 percent confidence intervals for Lost River suckers from the lakeshore spawning subpopulation, 1999-2009. The 2001 estimates of $\Phi$ were on the boundary at 1.0 and are not shown, as they indicate estimability problems. 

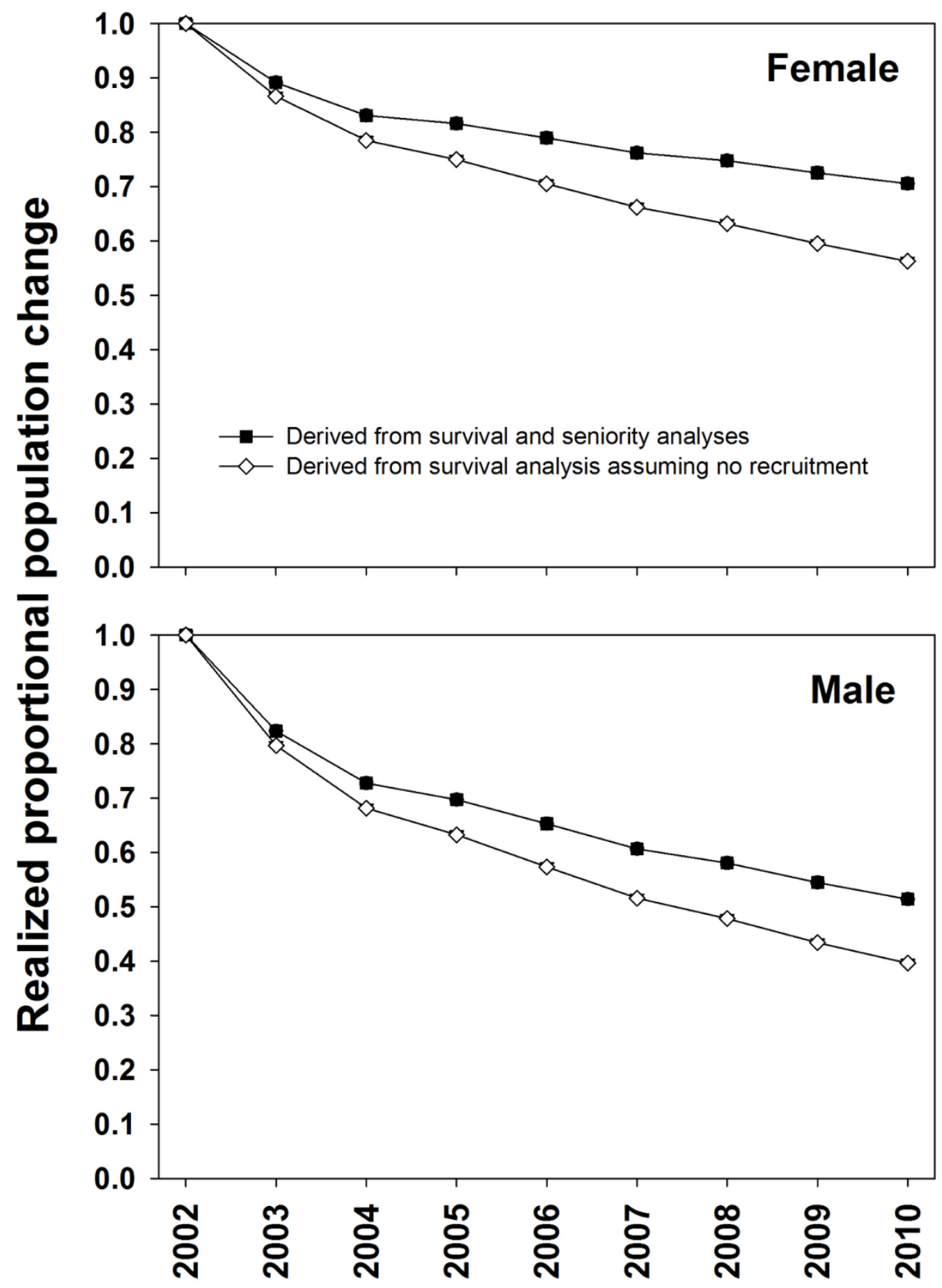

Figure 8. Realized proportional change in the size of the lakeshore spawning subpopulation of Lost River suckers between 2002 and 2010. The filled squares show annual changes based on lambda estimates derived from separate models of apparent annual survival (CJS likelihood) and seniority (reverse time CJS likelihood), using all encounters for survival estimates and physical captures only for seniority estimates. The open diamonds show annual changes assuming no recruitment, a worst case scenario but one that is plausible based on evidence from size composition data. 

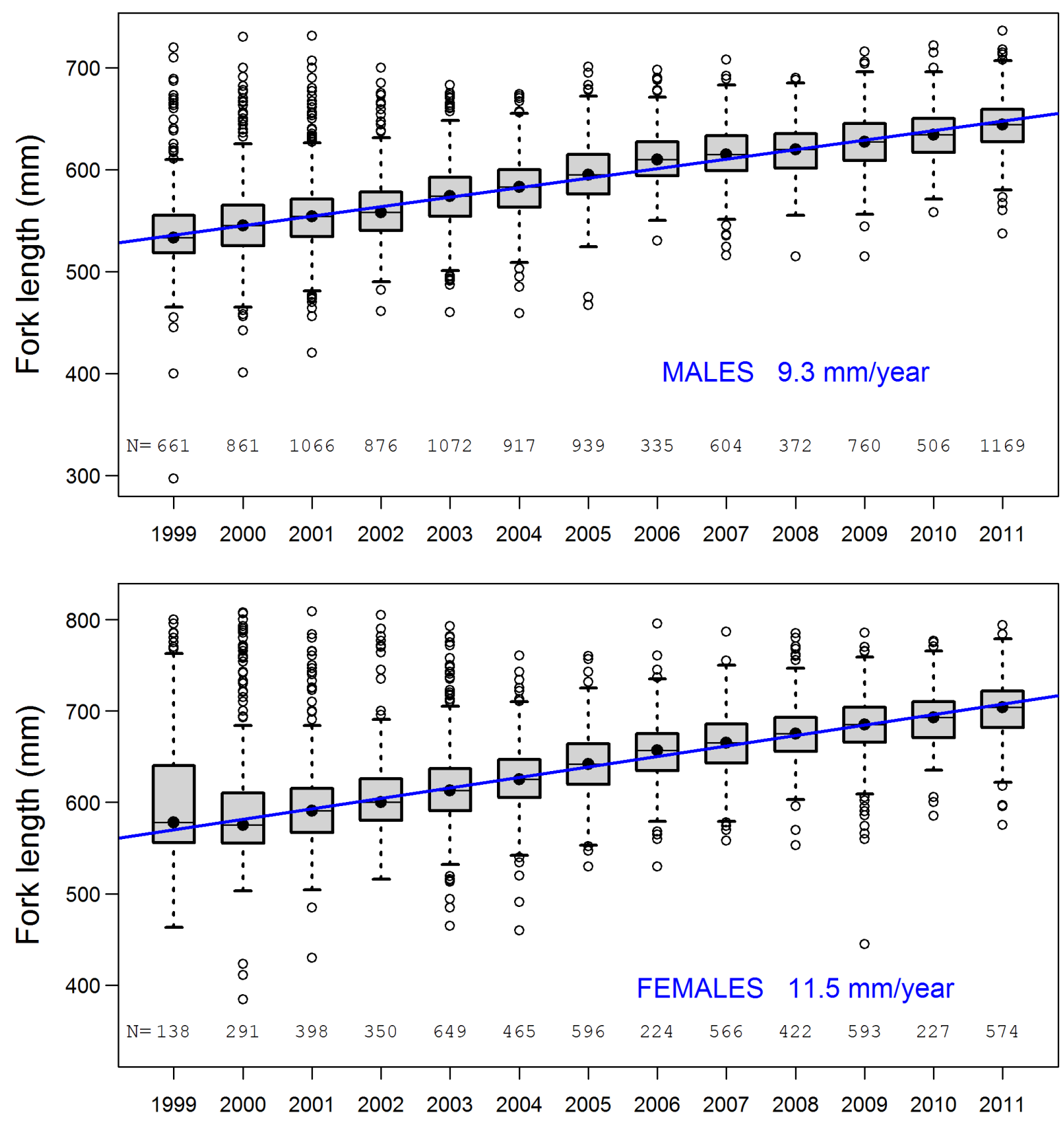

Figure 9. Boxplots of fork lengths of male (top) and female (bottom) Lost River suckers captured in trammel nets at lakeshore springs, 1999-2011. Dots in the boxes represent the medians and the boxes cover the central 75 percent of the data. The number of fish included in the boxplots for each year are given near the $x$-axis in each panel. The trend lines are simple linear regressions through the medians and the slope of the line for each sex is given as an average annual growth rate. 

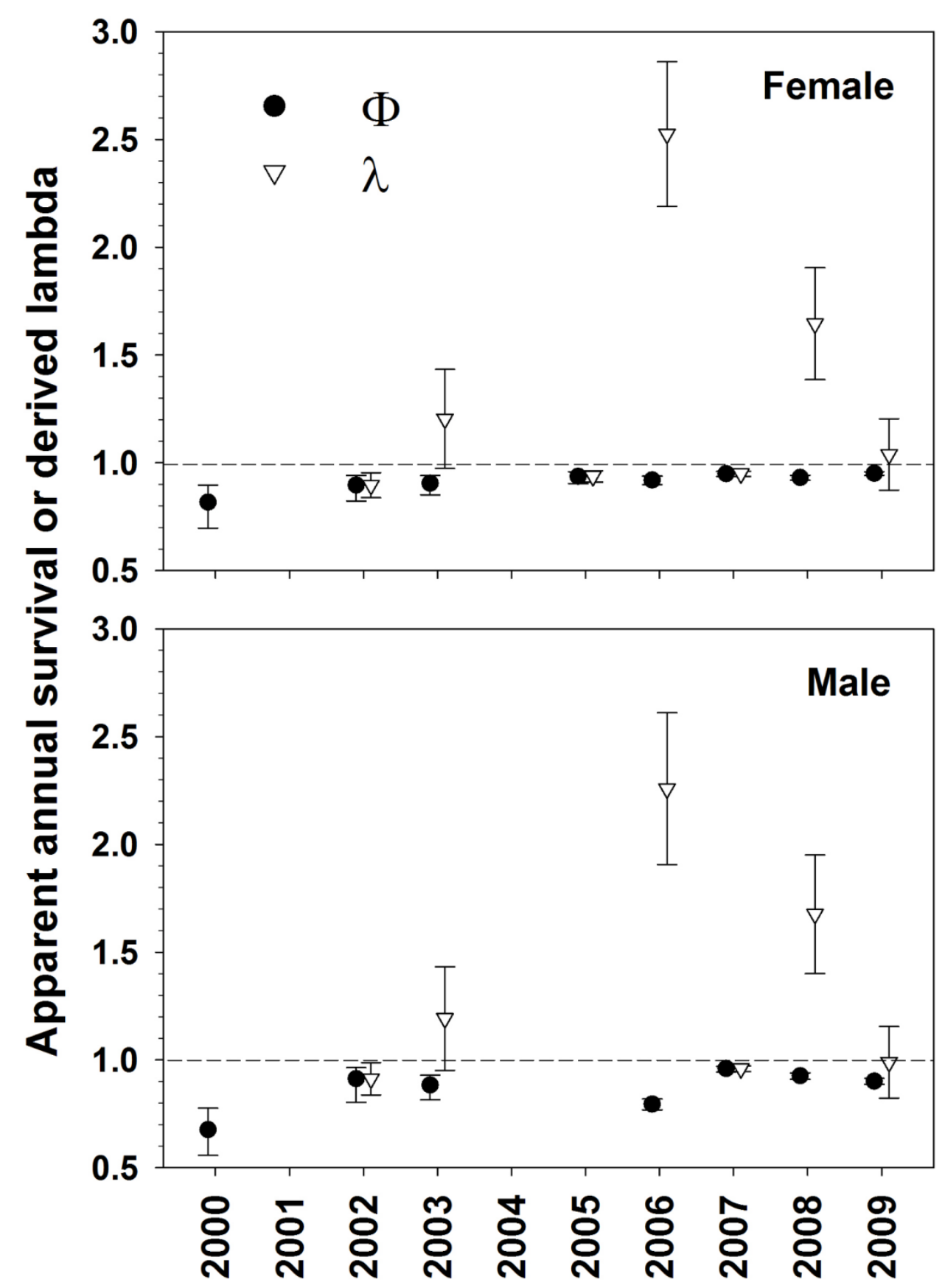

Figure 10. Model-averaged estimates of apparent annual survival probability $(\Phi)$ and derived population rate of change $(\lambda)$ with 95 percent confidence intervals for Lost River suckers from the river spawning subpopulation, 2000-2009. Estimates of $\Phi$ were either on the boundary at 1.0 or were so imprecise that they were not useful for both sexes in 2001 and 2004, and for males in 2005. Estimates of $\gamma$ for both sexes were on the boundary at 1.0 in 2004 and 2005. 

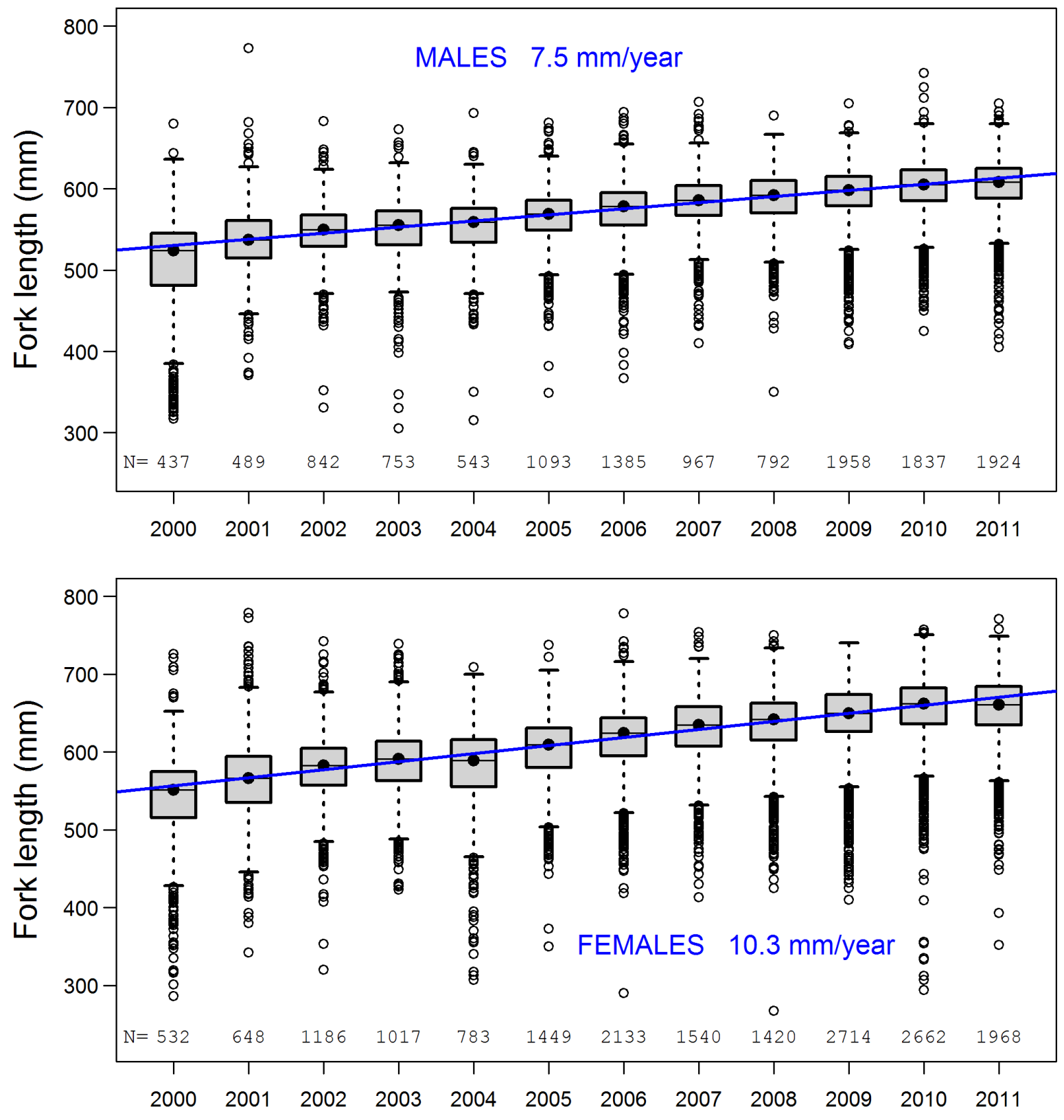

Figure 11. Boxplots of fork lengths of male (top) and female (bottom) Lost River suckers captured at pre-spawn staging areas in Upper Klamath Lake and in the Williamson and Sprague Rivers, 2000-2011. Dots in the boxes represent the medians and the boxes cover the central 75 percent of the data. The number of fish included in the boxplots for each year are given near the $x$-axis in each panel. The trend lines are simple linear regressions through the medians and the slope of the line for each sex is given as an average annual growth rate. 

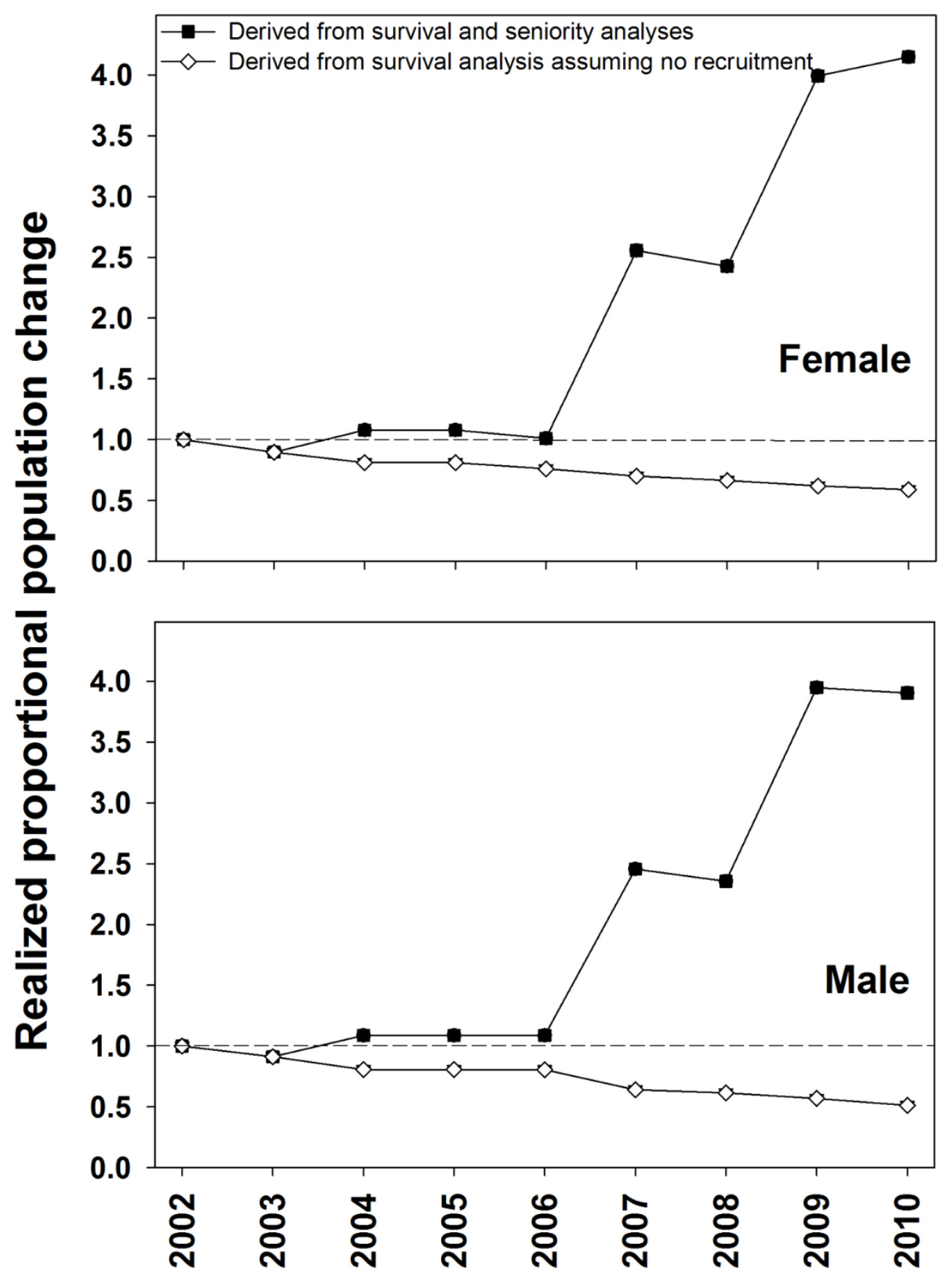

Figure 12. Realized proportional change in the size of the river spawning subpopulation of Lost River suckers between 2002 and 2010. The filled squares show annual changes based on lambda estimates derived from separate models of apparent annual survival (CJS likelihood) and seniority (reverse time CJS likelihood), using all encounters for survival estimates and physical captures only for seniority estimates. The open diamonds show annual changes assuming no recruitment, a worst case scenario but one that is plausible based on evidence from size composition data. 

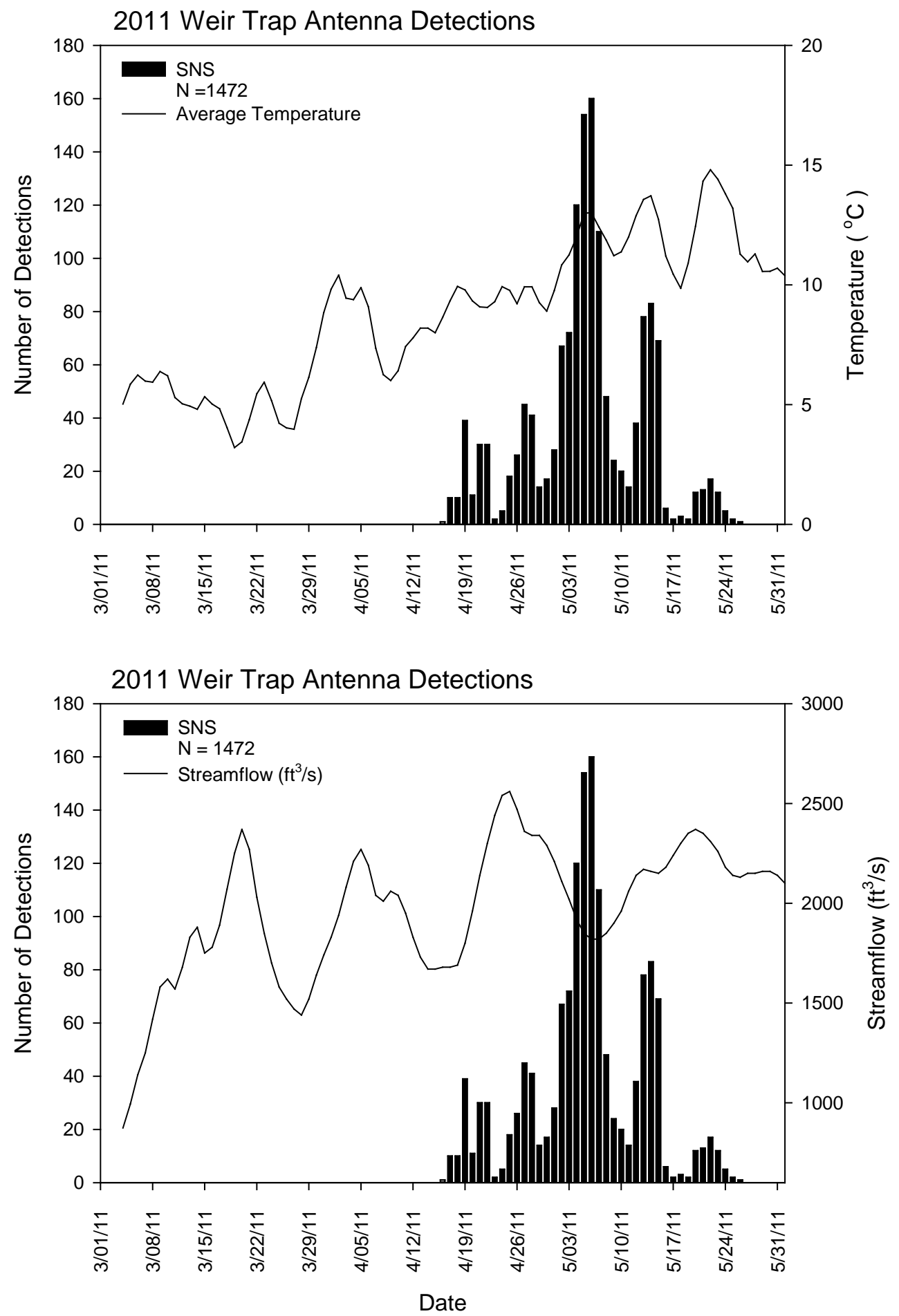

Figure 13. Seasonality of detections of shortnose suckers on the remote passive integrated transponder (PIT) tag antenna at the upstream trap of the Williamson River weir in 2011. If fish were detected more than once, only the first detection is included. Average daily water temperature $\left({ }^{\circ} \mathrm{C}\right)$ and streamflow $\left(\mathrm{ft}^{3} / \mathrm{s}\right)$ are reported from the USGS gage on the Williamson River downstream of the confluence with the Sprague River near Chiloquin, Oregon (11502500). 

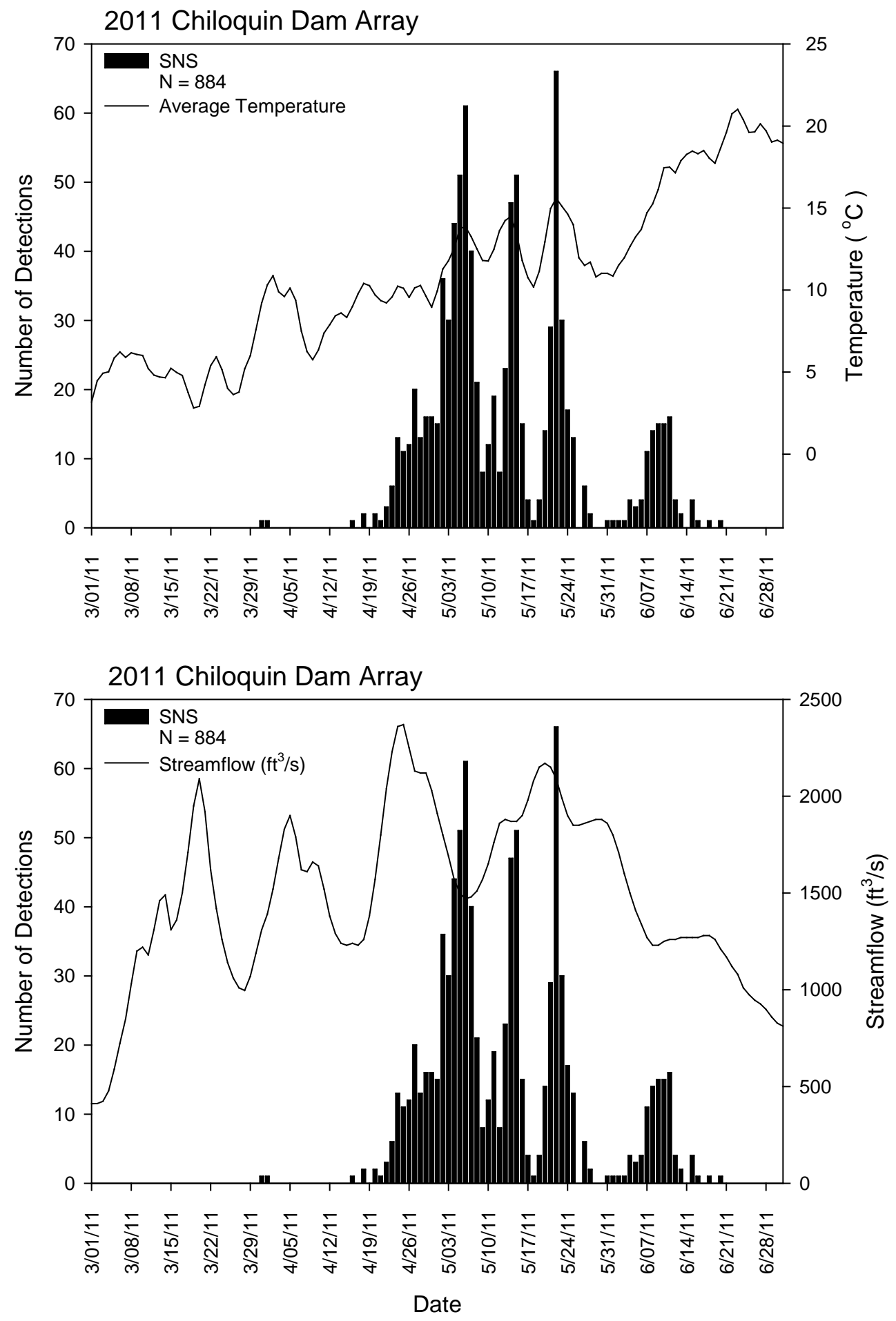

Figure 14. Seasonality of detections of shortnose suckers on the remote passive integrated transponder (PIT) tag antenna array across the Sprague River just downstream of the Chiloquin Dam site in 2011. If fish were detected more than once, only the first detection is included. Average daily water temperature $\left({ }^{\circ} \mathrm{C}\right)$ and streamflow $\left(\mathrm{ft}^{3} / \mathrm{s}\right)$ are reported from the USGS gage on the Sprague River upstream of the confluence with the Williamson River, upstream of Chiloquin, Oregon (11501000). 


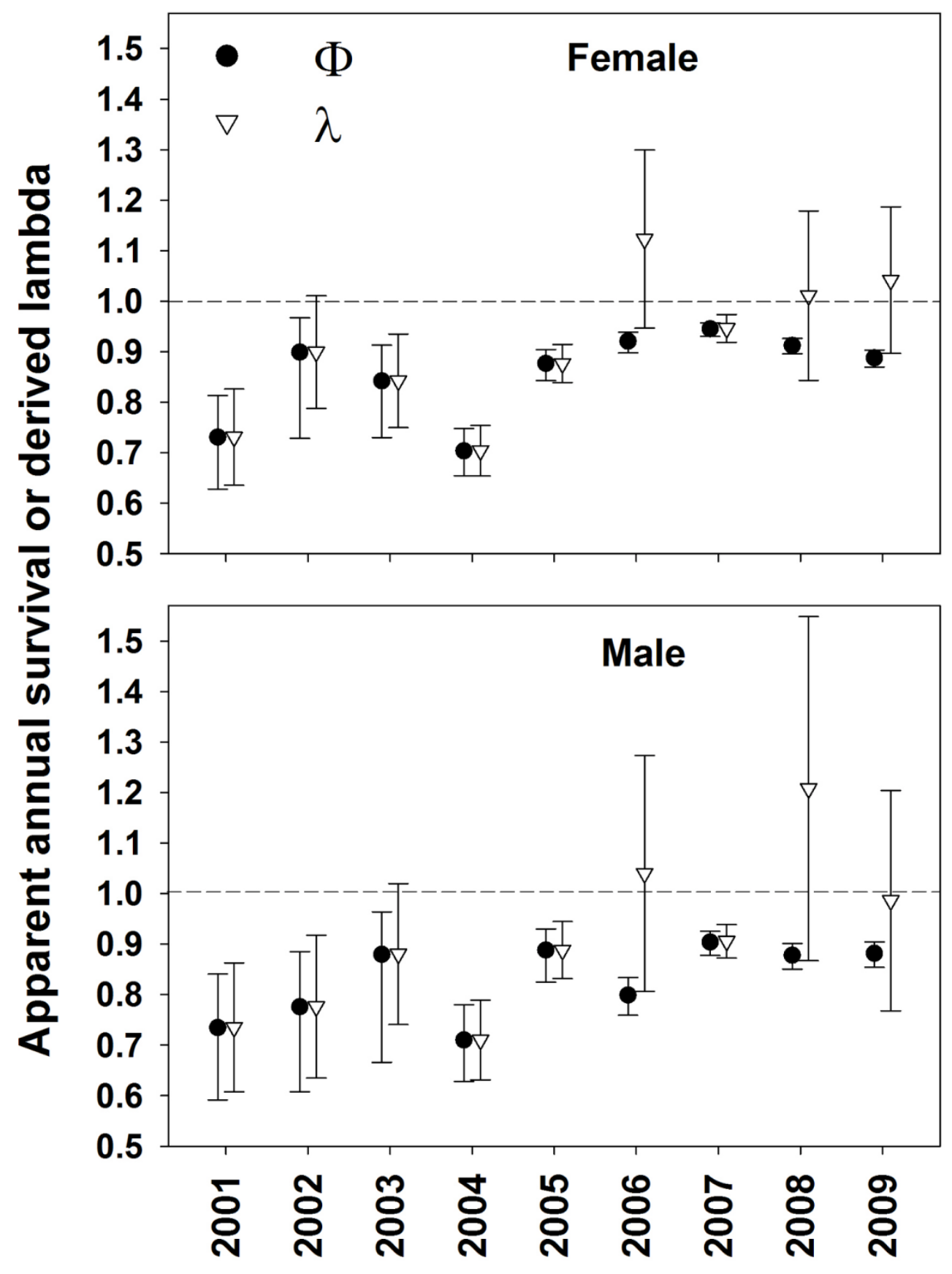

Figure 15. Model-averaged estimates of apparent annual survival probability $(\Phi)$ and derived population rate of change $(\lambda)$ with 95 percent confidence intervals for shortnose suckers, 2001-2009. The estimates of $\Phi$ in 1999 and 2000 were either on the boundary at 1.0 or were so imprecise that they were not useful, so they are not shown. 

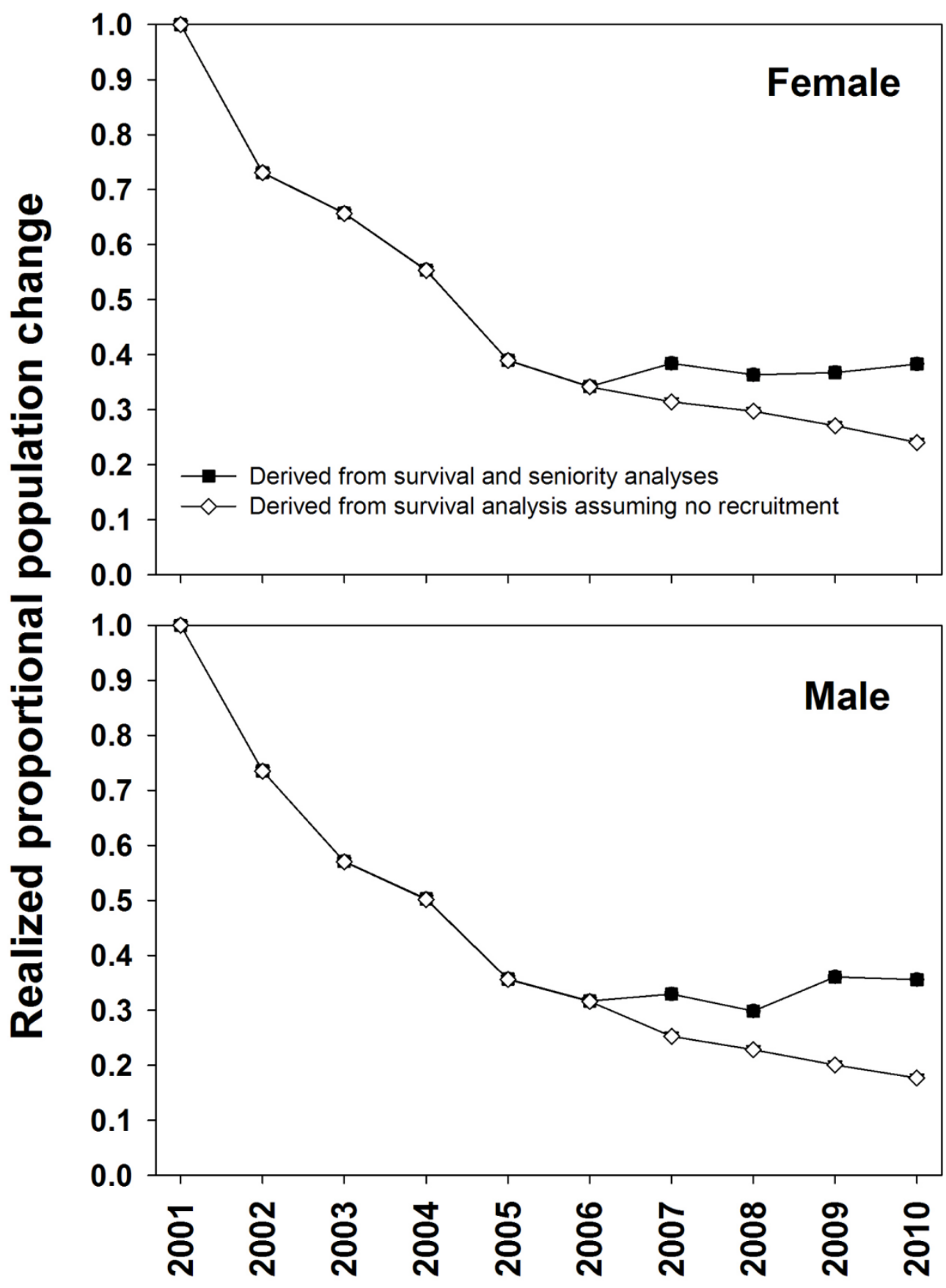

Figure 16. Realized proportional change in the size of the spawning population of shortnose suckers between 2001 and 2010. The filled squares show annual changes based on lambda estimates derived from separate models of apparent annual survival (CJS likelihood) and seniority (reverse time CJS likelihood), using all encounters for survival estimates and physical captures only for seniority estimates. The open diamonds show annual changes assuming no recruitment, a worst case scenario but one that is plausible based on evidence from size composition data. 

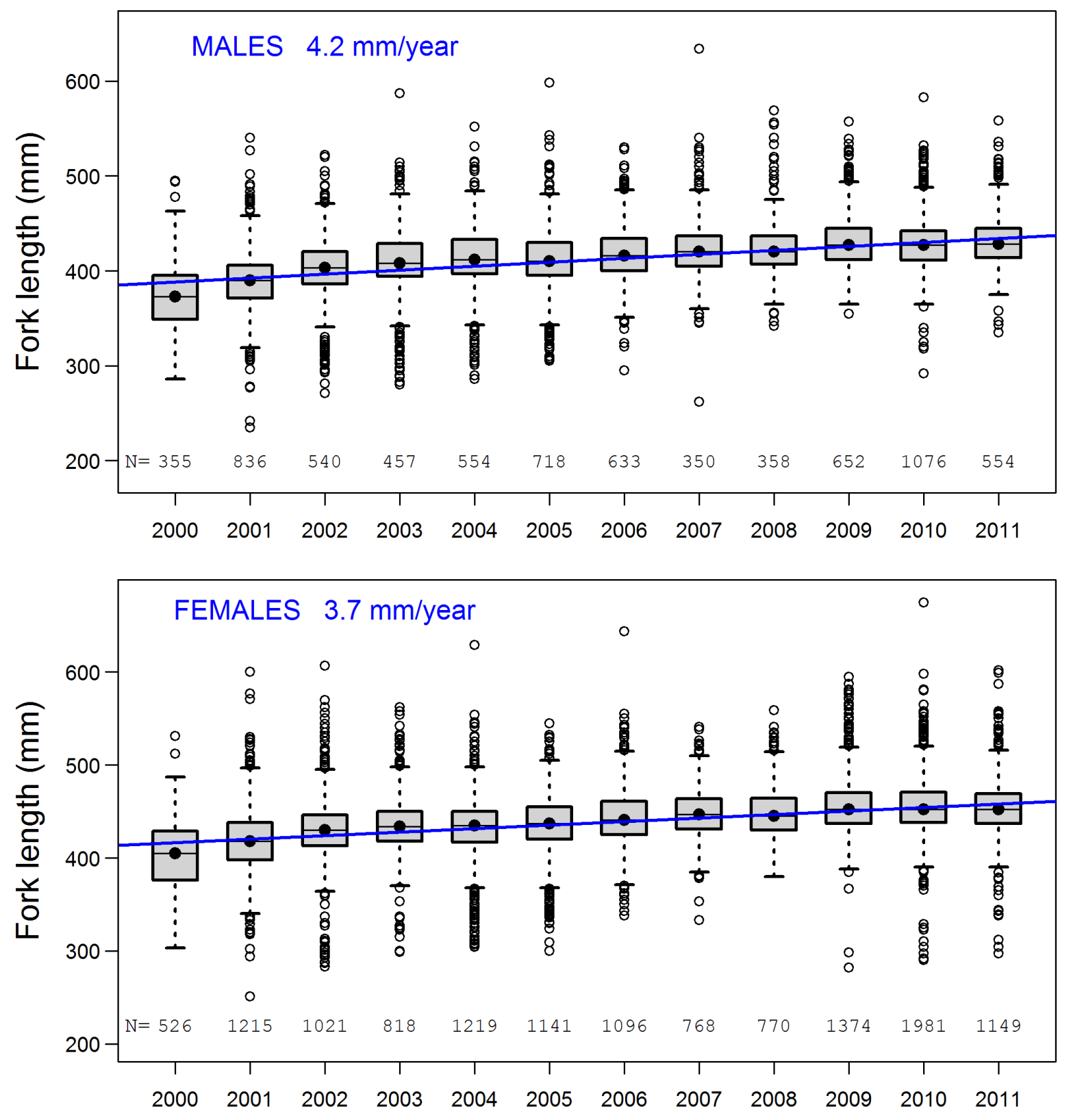

Figure 17. Boxplots of fork lengths of male (top) and female (bottom) shortnose suckers captured in Upper Klamath Lake and the Williamson and Sprague Rivers, 2000-2011. Dots in the boxes represent the medians and the boxes cover the central 75 percent of the data. The number of fish included in the boxplots for each year are given near the $x$-axis in each panel. The trend lines are simple linear regressions through the medians and the slope of the line for each sex is given as an average annual growth rate. 
Table 1. Numbers of Lost River suckers and shortnose suckers captured in Upper Klamath Lake (UKL) and the Williamson River between 2003 and 2011.

[Totals only include the first capture of an individual at a given location, but individuals may have been captured at more than one location in a year. Recaptures are the percentage of individuals captured in a given year that were implanted with a passive integrated transponder (PIT) tag in a previous year. High flows in the Williamson River in 2006 inundated the weir and allowed fish to pass over and around the weir without swimming through the trap]

\begin{tabular}{lccccc}
\hline Capture location & Year & $\begin{array}{c}\text { Lost River } \\
\text { suckers }\end{array}$ & Recaptures & $\begin{array}{c}\text { Shortnose } \\
\text { suckers }\end{array}$ & Recaptures \\
\hline UKL Pre-spawn Staging Areas & 2011 & 875 & $22 \%$ & 1,600 & $36 \%$ \\
& 2010 & 1,529 & $17 \%$ & 2,952 & $28 \%$ \\
& 2009 & 1,544 & $13 \%$ & 1,764 & $25 \%$ \\
& 2008 & 461 & $12 \%$ & 663 & $19 \%$ \\
& 2007 & 332 & $8 \%$ & 789 & $21 \%$ \\
& 2006 & 434 & $8 \%$ & 868 & $16 \%$ \\
& 2005 & 471 & $7 \%$ & 385 & $12 \%$ \\
Williamson River Weir & 2004 & 929 & $6 \%$ & 1,402 & $11 \%$ \\
& 2003 & 403 & $4 \%$ & 583 & $9 \%$ \\
\hline UKL Lakeshore Springs & 2011 & 3,118 & $12 \%$ & 181 & $32 \%$ \\
& 2010 & 3,085 & $9 \%$ & 214 & $24 \%$ \\
& 2009 & 3,275 & $8 \%$ & 367 & $22 \%$ \\
& 2008 & 1,316 & $7 \%$ & 282 & $22 \%$ \\
& 2007 & 2,047 & $6 \%$ & 235 & $14 \%$ \\
& 2006 & -- & -- & -- & - \\
& 2005 & 815 & $2 \%$ & 202 & $13 \%$ \\
\hline & 2011 & 1,812 & $56 \%$ & 3 & $33 \%$ \\
& 2009 & 752 & $51 \%$ & 10 & $60 \%$ \\
& 2008 & 1,419 & $45 \%$ & 7 & $57 \%$ \\
& 2007 & 1,210 & $44 \%$ & 3 & $100 \%$ \\
& 2006 & 578 & $36 \%$ & $63 \%$ & $37 \%$ \\
\hline
\end{tabular}


Table 2. Numbers of Lost River suckers and shortnose suckers detected by remote antennas in Upper Klamath Lake (UKL) and its tributaries in 2011.

[Totals only include the first detection of an individual at a given location, but individuals may have been detected at more than one location]

\begin{tabular}{lcrr}
\hline $\begin{array}{c}\text { Location of remote } \\
\text { antennas }\end{array}$ & Lost River suckers & Shortnose suckers & Total \\
\hline Williamson and Sprague Rivers & & & \\
\hline Williamson River Weir & 16,213 & 5,267 & 21,480 \\
Chiloquin Dam Array & 5,094 & 862 & 5,956 \\
Above Dam Array & 974 & 483 & 1,457 \\
Braymill Array & 70 & 19 & 89 \\
\hline UKL Lakeshore Springs & & 8 & 4,388 \\
\hline Cinder Flats & 4,380 & 10 & 3,019 \\
Ouxy Springs & 3,009 & 9 & 3,544 \\
Silver Building Springs & 3,535 & 23 & 4,283 \\
Sucker Springs & 4,260 & & \\
\hline
\end{tabular}


Table 3. Model selection results for the top eight capture-recapture models fitted to the data for the lakeshore spawning subpopulation of Lost River suckers, 1999-2011.

[Akaike's Information Criterion corrected for small sample size and overdispersion (quasilikelihood AICc [QAICc]) was used to compare the candidate models of survival $(\phi)$ and re-encounter $(p)$ probabilities (overdispersion correction factor [c] $=1.66$ ). Twenty-seven other models were considered, but all had $\Delta \mathrm{QAICc}>49$ and are not shown. In the model names, a $\times$ symbol indicates fully interactive effects and the + symbol indicates additive effects. The tagtype effect on $p$ in the model name refers to the difference between $125 \mathrm{kHz}$ and $134.2 \mathrm{kHz}$ PIT tags, which is only included for 2006 through 2011 . The tagtype effect is either constrained to be the same across years (tagtype alone) or allowed to vary by year (tagtype $\times$ time). Both structures were combined additively (+ precedes tagtype) and interactively (× precedes tagtype) with the other effects in the models. The best model is presented first, and $\triangle$ QAICc values represent the difference between the QAICc value of a given model and that of the best model. Akaike weights $\left(w_{i}\right)$ provide a measure of each model's relative weight or likelihood of being the best model in the set given the data. Number of parameters $(K)$ is the total number that is theoretically estimable in the model]

\begin{tabular}{|c|c|c|c|c|c|}
\hline Model & $K$ & QAICc & $\triangle Q A I C c$ & $w_{i}$ & $-2 \log _{e} L$ \\
\hline$\phi($ sex + time $) p($ sex $\times$ time $+[$ tagtype $\times$ time $])$ & 42 & $32,099.6$ & 0.0 & 0.90 & $53,017.6$ \\
\hline$\phi($ sex $\times$ time $) p($ sex $\times$ time $+[$ tagtype $\times$ time $])$ & 52 & $32,104.5$ & 4.9 & 0.08 & $52,992.6$ \\
\hline$\phi($ sex + time $)$ p $($ sex $\times$ time $\times$ tagtype $)$ & 48 & $32,107.4$ & 7.8 & 0.02 & $53,010.7$ \\
\hline$\phi($ sex $\times$ time $) \mathrm{p}($ sex $\times$ time $\times$ tagtype $)$ & 58 & $32,112.3$ & 12.8 & 0.00 & $52,985.6$ \\
\hline$\phi($ sex + time $) p($ sex + time $+[$ tagtype $\times$ time $])$ & 31 & $32,119.1$ & 19.5 & 0.00 & $53,086.4$ \\
\hline$\phi($ sex $\times$ time $) p($ sex + time $+[$ tagtype $\times$ time $])$ & 41 & $32,122.3$ & 22.8 & 0.00 & $53,058.6$ \\
\hline$\phi($ sex + time $) \mathrm{p}($ sex $\times$ time + tagtype $)$ & 37 & $32,126.3$ & 26.7 & 0.00 & $53,078.5$ \\
\hline$\phi($ sex $\times$ time $) p($ sex $\times$ time + tagtype $)$ & 47 & $32,131.1$ & 31.5 & 0.00 & $53,053.2$ \\
\hline
\end{tabular}


Table 4. Model selection results for the top five capture-recapture models fitted to the data for the river spawning subpopulation of Lost River suckers, 2000-2011.

[Akaike's Information Criterion corrected for small sample size and overdispersion (quasilikelihood AICc [QAICc]) was used to compare the candidate models of survival $(\phi)$ and re-encounter $(p)$ probabilities (overdispersion correction factor [ $\hat{c}$ ] $=2.18$ ). Thirty other models were considered, but all had $\Delta$ QAICc $>75$ and are not shown. See the caption note for table 3 for a complete description of table contents]

\begin{tabular}{|c|c|c|c|c|c|}
\hline Model & $K$ & QAICC & $\triangle Q A I C c$ & $w_{i}$ & $-2 \log _{e} L$ \\
\hline$\phi($ sex $\times$ time $) \mathrm{p}($ sex $\times$ time $\times$ tagtype $)$ & 54 & $38,150.4$ & 0.00 & 1.00 & $83,084.5$ \\
\hline$\phi($ sex $\times$ time $) p($ sex $\times$ time $+[$ tagtype $\times$ time $])$ & 48 & $38,170.3$ & 19.85 & 0.00 & $83,154.1$ \\
\hline$\phi($ sex + time $) \mathrm{p}($ sex $\times$ time $\times$ tagtype $)$ & 45 & $38,178.8$ & 28.40 & 0.00 & $83,185.9$ \\
\hline$\phi($ sex + time $) p($ sex $\times$ time $+[$ tagtype $\times$ time $])$ & 39 & $38,200.7$ & 50.21 & 0.00 & $83,259.8$ \\
\hline$\phi($ sex $\times$ time $) p($ sex + time $+[$ tagtype $\times$ time $])$ & 38 & $38,209.3$ & 58.80 & 0.00 & $83,282.9$ \\
\hline
\end{tabular}


Table 5. Model selection results for the top nine capture-recapture models fitted to the data for the shortnose sucker population, 1999-2011.

[Akaike's Information Criterion corrected for small sample size and overdispersion (quasilikelihood AICc [QAICc]) was used to compare the candidate models of survival $(\phi)$ and re-encounter $(p)$ probabilities (overdispersion correction factor [ $\hat{c}$ ] $=1.56$ ). Twenty-six other models were considered, but all had $\Delta \mathrm{QAICc}>298$ and are not shown. See the caption note for table 3 for a complete description of table contents]

\begin{tabular}{|c|c|c|c|c|c|}
\hline Model & $K$ & QAICC & $\triangle Q A I C C$ & $w_{i}$ & $-2 \log _{e} L$ \\
\hline$\phi($ sex $\times$ time $) \mathrm{p}($ sex + time $+[$ tagtype $\times$ time $])$ & 41 & $38,002.5$ & 0.0 & 0.99 & $59,155.9$ \\
\hline$\phi($ sex $\times$ time $) \mathrm{p}($ sex $\times$ time $+[$ tagtype $\times$ time $])$ & 52 & $38,011.9$ & 9.4 & 0.01 & $59,136.1$ \\
\hline$\phi($ sex $\times$ time $) \mathrm{p}($ sex $\times$ time $\times$ tagtype $)$ & 58 & $38,015.3$ & 12.7 & 0.00 & $59,122.5$ \\
\hline$\phi($ sex + time $) p($ sex $\times$ time $+[$ tagtype $\times$ time $])$ & 42 & $38,025.2$ & 22.7 & 0.00 & $59,188.1$ \\
\hline$\phi($ sex + time $) p($ sex + time $+[$ tagtype $\times$ time $])$ & 31 & $38,025.8$ & 23.2 & 0.00 & $59,223.4$ \\
\hline$\phi($ sex + time $) \mathrm{p}($ sex $\times$ time $\times$ tagtype $)$ & 48 & $38,029.0$ & 26.4 & 0.00 & $59,175.2$ \\
\hline$\phi($ time $) \mathrm{p}($ sex $\times$ time $+[$ tagtype $\times$ time $])$ & 41 & $38,048.0$ & 45.4 & 0.00 & $59,226.7$ \\
\hline$\phi($ time $) \mathrm{p}($ sex $\times$ time $\times$ tagtype $)$ & 47 & $38,054.4$ & 51.9 & 0.00 & $59,218.0$ \\
\hline$\phi($ time $) \mathrm{p}($ sex + time $+[$ tagtype $\times$ time $])$ & 30 & $38,055.3$ & 52.7 & 0.00 & $59,272.5$ \\
\hline
\end{tabular}


Publishing support provided by the U.S. Geological Survey

Publishing Network, Tacoma Publishing Service Center

For more information concerning the research in this report, contact the Director, Western Fisheries Research Center

U.S. Geological Survey

6505 NE 65th Street

Seattle, WA 98115

http://wfrc.usgs.gov/ 


\section{㞭}

논.

ฏ

흠

蛋

謨

롤.

咅

좉

言.

를

:

ग्र્ર

를

흠

言

홋

产 